TecnoLógicas

ISSN-p 0123-7799

ISSN-e 2256-5337

Vol. 23, No. 47, pp. 23-61

Enero-abril de 2020

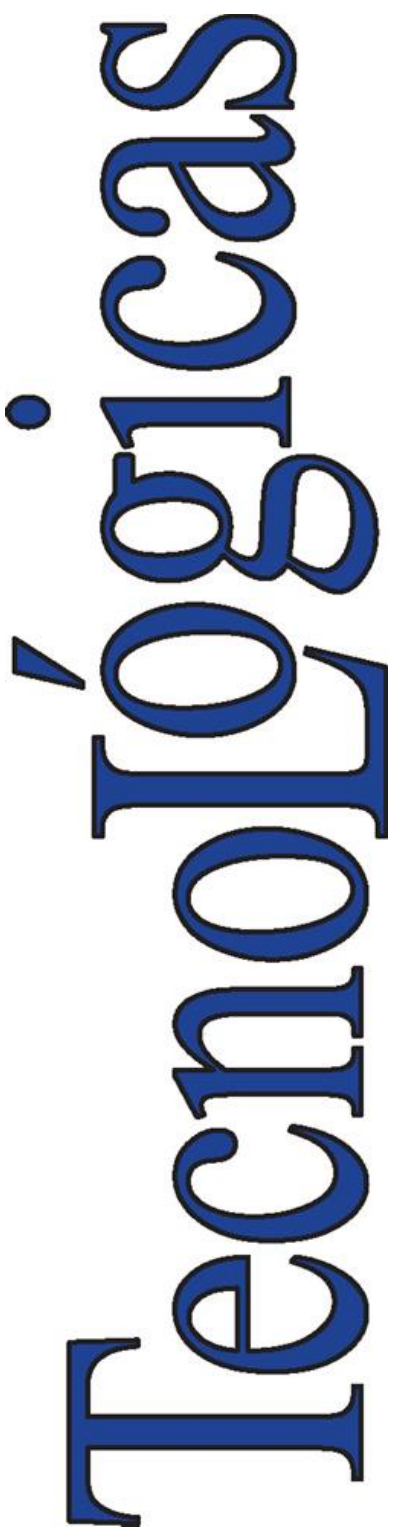

(C) Instituto Tecnológico Metropolitano Este trabajo está licenciado bajo una Licencia Internacional Creative Commons Atribución (CC BY-NC-SA)

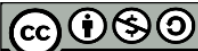

Artículo de Investigación/Research Article

\section{Evaluación del desempeño físico de un sistema FTTH-GPON para servicios Quad Play después de la incorporación de un módulo RoF}

\section{Evaluation of the Physical Performance of an FTH-GPON System for Quad Play Services After the Incorporation of an RoF Module}

Recibido: 27 de junio de 2019 Aceptado: 04 de octubre de 2019

Cómo citar / How to cite

A. F. Escallón-Portilla, V. H. Ruíz-Guachetá, y J. G. López-Perafán, "Evaluación del desempeño físico de un sistema FTTH-GPON para servicios Quad Play después de la incorporación de un módulo RoF,”. TecnoLógicas, vol. 23, no. 47, pp. 23-61, 2020.

https://doi.org/10.22430/22565337.1391

1 MSc. en Telecomunicaciones, Facultad de Ingeniería Electrónica y Telecomunicaciones, Universidad del Cauca, Popayán-Colombia, aescallon@unicauca.edu.co

2 MSc. en Telecomunicaciones, Facultad de Ingeniería Electrónica y Telecomunicaciones, Universidad del Cauca, Popayán-Colombia, vruiz@unicauca.edu.co

3 PhD. en Ciencias de la Electrónica, Facultad de Ingeniería Electrónica y Telecomunicaciones, Universidad del Cauca, Popayán-Colombia, glopez@unicauca.edu.co 


\section{Resumen}

Este artículo propone el diseño y simulación de un módulo de radio frecuencia basado en un sistema de multiplexación por división de frecuencia ortogonal (OFDM) con modulación de amplitud en cuadratura (16-QAM) a una tasa de transmisión de datos de 10 Gbps y a una frecuencia de $10 \mathrm{GHz}$, utilizando la herramienta de simulación OptSim. Para ello, se diseñó a nivel de simulación un sistema de red con fibra hasta el hogar (FTTH)-óptica pasiva Gigabit (GPON) Triple Play (servicio de datos/voz a 2,5 Gbps y servicio de video CATV digital con 16-QAM a 0,8 Gbps) con el fin de integrar el módulo de radio sobre fibra (RoF) para ofrecer servicios Quad Play (Triple Play más Internet móvil). Posteriormente, se evaluó el desempeño para el enlace descendente a nivel físico del sistema FTTH-GPON después de que se incorporó el módulo RoF, con base en los parámetros de monitoreo de desempeño óptico (OPM), tales como: potencia de recepción óptica, magnitud del vector de error (EVM), diagrama de constelación, relación señal a ruido (SNR), tasa de error de bit (BER), Factor de calidad (Q) y diagrama del ojo. Los resultados muestran que es posible que los usuarios de las redes FTTH-GPON puedan contar, además de los servicios Triple Play, con un cuarto servicio (Internet móvil) ya que la calidad del servicio móvil está garantizada dentro del "último kilómetro" para redes de acceso, usando el despliegue actual de fibra óptica estándar, demostrando la factibilidad del sistema propuesto.

\section{Palabras clave}

Fibra hasta la casa, red óptica pasiva Gigabit, radio sobre fibra, multiplexación por división de frecuencia ortogonal, modulación de amplitud en cuadratura, monitoreo de desempeño óptico, magnitud del vector de error.

\section{Abstract}

This article proposes the design and simulation of a radio frequency module based on an Orthogonal Frequency Division Multiplexing (OFDM) system with Quadrature Amplitude Modulation (16-QAM) at a data transmission rate of $10 \mathrm{Gbps}$ and a frequency of $10 \mathrm{GHz}$ using the simulation tool OptSim. For that purpose, a Fiber To The Home (FTTH)-Gigabit Passive Optical Network (GPON) Triple Play system (voice/data service at 2,5 Gbps and digital CATV video service with 16-QAM at 0,8 Gbps) was designed in order to integrate a Radio over Fiber (RoF) module and offer Quad Play services (Triple Play plus mobile Internet). Subsequently, the physical performance of the downlink of the FTTH-GPON system was evaluated after the RoF module was incorporated, based on Optical Performance Monitoring (OPM) parameters such as: Optical Receiver Power, Error Vector Magnitude (EVM), Constellation Diagram, Signal to Noise Ratio (SNR), Bit Error Rate (BER), Quality (Q) Factor, and Eye Diagram. The results show that it may be possible for FTTH-GPON users to have, in addition to Triple Play services, a fourth one (mobile Internet) because the quality of the mobile service is guaranteed within the "last kilometer" for access networks using the current deployment of standard optical fiber, demonstrating the feasibility of the proposed system.

\section{Keywords}

Fiber to the home, Gigabit passive optical network, radio over fiber, orthogonal frequency division multiplexing, quadrature amplitude modulation, optical performance monitoring, error vector magnitude. 


\section{INTRODUCCIÓN}

De acuerdo con [1], la revolución de la industria de telecomunicaciones a partir del desarrollo de Internet ha sido de tal magnitud que la convergencia tecnológica es una realidad actualmente. El desarrollo de la tecnología ha posibilitado el hecho de que las aplicaciones como texto, imagen, video y audio, convivan dentro de una misma red. Esto ha generado y demandado nuevos usos para los distintos dispositivos conectados. El teléfono celular brinda cada vez más prestaciones y se convierte en un dispositivo multimedia inteligente, que permite múltiples servicios para satisfacer las necesidades de los usuarios finales.

Por otro lado, con el avance y desarrollo de la digitalización se ha permitido un uso más eficiente de las redes de telecomunicaciones, que cada día tiene costos menores y, a su vez, se impulsa el desarrollo de nuevos servicios y aplicaciones, como por ejemplo servicios de video bajo demanda, foto blogs, video logs, descargas y streaming de video, plataformas de televisión digital y puesta en línea de contenidos. Todo esto está generando la oferta al consumidor de una experiencia nueva, brindando a los usuarios los servicios requeridos con las mejores condiciones en el momento y en el lugar donde se encuentren [1].

Numerosos proveedores de contenidos de todo el planeta están usando Internet para llegar con su programación a los sitios más alejados, disponiendo de esta manera de una plataforma alternativa de mucho más potencial y alcance. Estos proveedores de telecomunicaciones, en gran parte del globo, ofrecen servicios Triple Play y algunos ya hablan de servicios X-Play para el usuario final. Estos servicios se ofrecen a través de Internet teniendo que disponer para ello de una plataforma robusta $\mathrm{y}$ competitiva para dicho fin [1], [2].

En concordancia con lo mencionado en [3], los usuarios finales están demandando una gran velocidad de transmisión de datos en sus dispositivos móviles, que les garantice una conectividad inalámbrica permanente y no tener la necesidad de dirigirse a puntos de acceso cableados. Sin embargo, los servicios inalámbricos no están en la capacidad de proporcionar grandes transmisiones de datos, debido a que no poseen suficiente ancho de banda. Hoy por hoy, las redes Gibabit Ethernet (GbE) proporcionan hasta 1 Gbps para sistemas inalámbricos y ya se están haciendo investigaciones para la implementación de $10 \mathrm{GbE}$.

Cabe notar también que para transmisiones a velocidades del orden de los multi-Gbps, se encuentran en estudio los diferentes y posibles escenarios para implementar sistemas inalámbricos operando con portadoras a frecuencias extremadamente altas (EHF), cuyo rango oscila entre 30 y $300 \mathrm{GHz}$.

Este rango de frecuencias se conoce en la comunidad científica como la banda de ondas milimétricas $(\mathrm{mmW})$, el cual proporciona más ancho de banda en el rango de los $\mathrm{GHz}$. Citando a países desarrollados como Estados Unidos y Corea del Sur, el uso de la frecuencia de 60 $\mathrm{GHz}$ cada día se está masificando.

Por ese motivo, se está estudiando el ancho de banda de los sistemas inalámbricos que operan alrededor de 60 $\mathrm{GHz}$ a nivel mundial; por ejemplo, el grupo IEEE 802.15.3c se enfoca en distancias de transmisión de corto alcance de hasta $10 \mathrm{~m}$ y se proponen sistemas inalámbricos internos en el rango de las mmW para el suministro de velocidades mayores a 1 Gbps. Para el desarrollo de sistemas que trabajen en bandas de $\mathrm{mmW}$ se presentan problemas, como el costo de los equipos electrónicos utilizados y el aumento de las estaciones base (BS) que deberían implementarse. Además, la transmisión de señales de $\mathrm{mmW}$ necesita mayor potencia, debido a las altas pérdidas en el medio inalámbrico, lo cual genera inconvenientes en la implementación. 
Algunos de estos inconvenientes se solucionan con la tecnología RoF, la cual se presenta como una de las soluciones más prometedoras para las redes de acceso en el mundo [3].

Por otra parte, los sistemas RoF que operan en la banda $\mathrm{mmW}$ requieren de celdas pequeñas debido a la corta distancia de propagación; de hecho, los enlaces de radio de $\mathrm{mmW}$ están siendo considerados para la implementación de sistemas micro o pico celulares de banda ancha, redes de acceso y redes inalámbricas internas [3].

Se tiene también que la demanda de tasas de trasmisión altas y gran ancho de banda en redes fijas e inalámbricas se ha incrementado en los últimos años $\mathrm{y}$ muestra un comportamiento similar en los años subsiguientes. Un estudio realizado por Cisco Systems publicó un reporte donde se pronosticaba que el tráfico de datos a nivel mundial para el año 2018 sobre del protocolo de Internet (IP) superaría el umbral del Zettabyte.

Según Cisco, durante el periodo 20122017 el tráfico del segmento metropolitano creció el doble que el tráfico de la red troncal; se predijo también que para el 2017 alrededor de la mitad del tráfico IP de consumo se generó en dispositivos que no son computadores personales y este creció alrededor del $49 \%$ en comparación con el $26 \%$ del año 2012. Con estos resultados se espera que para este año (2019) los dispositivos conectados a la red cableada representen aproximadamente el $45 \%$ del tráfico IP, mientras que el $55 \%$ de dicho tráfico estará generado por redes Wi-Fi y dispositivos móviles, lo que implicará un gran aumento de ancho de banda demandado por los dispositivos móviles [4], [5].

De acuerdo al análisis anterior, actualmente se observa que las redes de acceso ópticas pueden proporcionar un amplio ancho de banda para los usuarios finales, mientras que las redes inalámbricas ofrecen movilidad a los usuarios, pero no cumplen con los requerimientos de ancho de banda demandado por los mismos. Además, tener redes de acceso separadas genera altos costos de operación y mantenimiento para los proveedores de servicios.

Todo esto demanda la necesidad de una convergencia de dichas redes en una sola infraestructura compartida para la futura distribución de contenidos (X-Play) para usuarios fijos y móviles; con base en esto, los sistemas RoF y FTTH son las tecnologías más apropiadas para consolidarse en el segmento de redes de acceso inalámbrico y fijo, respectivamente, debido a la movilidad y al gran ancho de banda que soportan. A pesar de que los sistemas RoF se pueden implementar en redes troncales logrando cubrir grandes distancias, el gran atractivo de estos sistemas radica en que se pueden utilizar en redes de acceso inalámbrico de banda ancha que permita el transporte y la distribución de las portadoras de radio frecuencia $(\mathrm{RF})$ de cualquier red inalámbrica utilizando una infraestructura de red de acceso FTTH [4], [5].

Teniendo en cuenta este escenario, surge la pregunta y el desafío de cómo transmitir señales de RF en redes FTTHGPON, usando una sola longitud de onda sobre fibra, de manera que se garantice una calidad aceptable y que el costobeneficio sea atractivo [5].

Hasta el momento, se han realizado diferentes investigaciones y trabajos alrededor de sistemas RoF, en los cuales se muestran las ventajas de implementar dichos sistemas en diferentes escenarios y aplicaciones.

En [4] se hace un estudio comparativo de las técnicas de generación de señales para el transporte de información sobre sistemas RoF usando técnicas de combinación óptica, mientras que en [3] se discute las tecnologías que permiten desarrollar los sistemas RoF, y en [5] se realiza el análisis de un modelo analítico para la generación de señales para sistemas RoF. 
En un trabajo previo [6], los autores realizaron, a nivel de simulación usando la herramienta Optiwave, e implementaron a nivel de laboratorio, un módulo RoF más complejo (transmisor a $24 \mathrm{GHz}$ linealizado digitalmente para el enlace de bajada de una red de acceso de radio en la nube) que el que se propone en el presente trabajo.

Ellos tuvieron en cuenta la no linealidad que presenta el modulador Mach-Zehnder (MZM), la cual fue mitigada, y usaron $35 \mathrm{~mW}$ de potencia en un tramo de $11,8 \mathrm{~km}$ de SMF-28 usando amplificación óptica, mientras que el enfoque usado en este artículo está dentro del contexto de redes ópticas pasivas, que no usan amplificadores y emplean potencias de transmisión bajas (desde 1 a menos de $10 \mathrm{~mW}$ ), además de no usar un MZM sino un modulador de electroabsorción (EAM) lineal para el módulo RoF propuesto.

Por su parte, en [7] se propone, se demuestra experimentalmente y se simula una arquitectura de red para el transporte de mmW basada en las técnicas de RoF para el transporte de señales en el segmento de fronthaul de los futuros sistemas 5G, mientras que en la presente investigación se trabaja desde 1 a 64 portadoras de radio OFDM/16-QAM a 10 $\mathrm{GHz}$ para un sistema FTTH-GPON Quad Play.

Según lo expresado anteriormente, y sabiendo que en Colombia cada día los usuarios demandan más ancho de banda por los múltiples servicios que utilizan en su diario vivir, se hace necesario realizar un estudio de los sistemas RoF aplicados a servicios Quad Play (voz, video, datos e Internet móvil) para tecnologías FTTHGPON.

Este estudio evalúa el desempeño a nivel físico de un sistema FTTH-GPON para servicios Quad Play al integrar un módulo RoF y lo simula en el entorno que ofrece la herramienta de simulación OptSim [8] para realizar el monitoreo de las señales que soportan los servicios Quad
Play, donde, según se sugiere en [9], [10], se debe tener en cuenta un adecuado monitoreo del canal óptico basado en OPM.

Este trabajo se organiza como sigue: la sección 2 presenta el marco teórico y el estado del arte. La sección 3 describe la metodología de desarrollo y simulación. La sección 4 muestra los resultados y discusión $\mathrm{y}$, finalmente, la sección 5 resume el estudio extrayendo las respectivas conclusiones.

\section{MARCO TEÓRICO Y ESTADO DEL ARTE}

Para el desarrollo metodológico de este trabajo de investigación se tuvo en cuenta referentes teóricos dentro de los cuales se destacan: principios de OFDM, tecnología FTTH-GPON y sistema de radio sobre fibra óptica RoF.

\subsection{Principios de OFDM}

En concordancia con [11], la técnica de modulación OFDM se utiliza actualmente en numerosas tecnologías dentro del contexto de las telecomunicaciones. OFDM es un gran avance para las comunicaciones digitales de banda ancha, tanto para guías ópticas o metálicas como para medios inalámbricos, ya que permite la transmisión de tasas binarias altas en canales de carácter hostil. Entre todas las ventajas que puede proporcionar esta modulación, se puede destacar principalmente la robustez que presenta ante los problemas que produce la propagación multitrayecto, un uso eficiente del espectro, la sencillez al realizar la modulación y demodulación mediante las transformada rápida inversa (IFFT) y directa (FFT) de Fourier, la flexibilidad para poder adaptarse a sistemas de gran ancho de banda gracias a la ecualización en el dominio de la frecuencia, la compatibilidad con técnicas de múltiples entradas y múltiples salidas (MIMO), además de la inserción de un prefijo cíclico 
(CP) que provoca la eliminación de los efectos producidos por la interferencia inter-simbólica (ISI).

Como principio primordial de OFDM está la división del espectro disponible en varios subcanales donde la información está modulada en múltiples portadoras, cada una a distinta frecuencia, como establece la técnica FDM, pero con la diferencia de que las portadoras son ortogonales entre sí [11]-[13].

\subsection{Tecnología FTH-GPON}

FTTH propone la utilización de fibra óptica hasta el domicilio del usuario. La red de acceso entre el abonado y el último nodo de distribución puede realizarse con una o dos fibras ópticas dedicadas a cada usuario (una conexión punto-punto que resulta en una topología en estrella) o una red óptica pasiva (PON) que usa una estructura arborescente con una fibra en el lado de la red y varias fibras en el lado usuario [14], [15], como se puede observar en la Fig. 1.
En la Fig. 1 se muestra una forma de proporcionar fibra hasta el hogar a través de una PON Gigabit (GPON), con la posibilidad de incluir a futuro servicios de conectividad a BS celulares.

GPON es una red de acceso punto a multipunto. Su principal característica es el uso de un divisor (splitter) pasivo en la red de distribución de fibra, lo que permite que una sola fibra de alimentación del proveedor sirva para múltiples hogares y pequeños negocios. GPON tiene una capacidad descendente de 2,5 Gbps y una capacidad ascendente de 1,25 Gbps que se comparte entre los usuarios [14], [15].

\subsection{Sistema de radio sobre fibra óptica (RoF)}

RoF es una tecnología que puede operar en cualquier banda de frecuencia, pero según el estado del arte, los principales estudios de estos sistemas se enfocan en la banda EHF (30-300 GHz o mmW). Dentro de estas frecuencias se operan anchos de banda de alrededor de $7 \mathrm{GHz}$ [16].

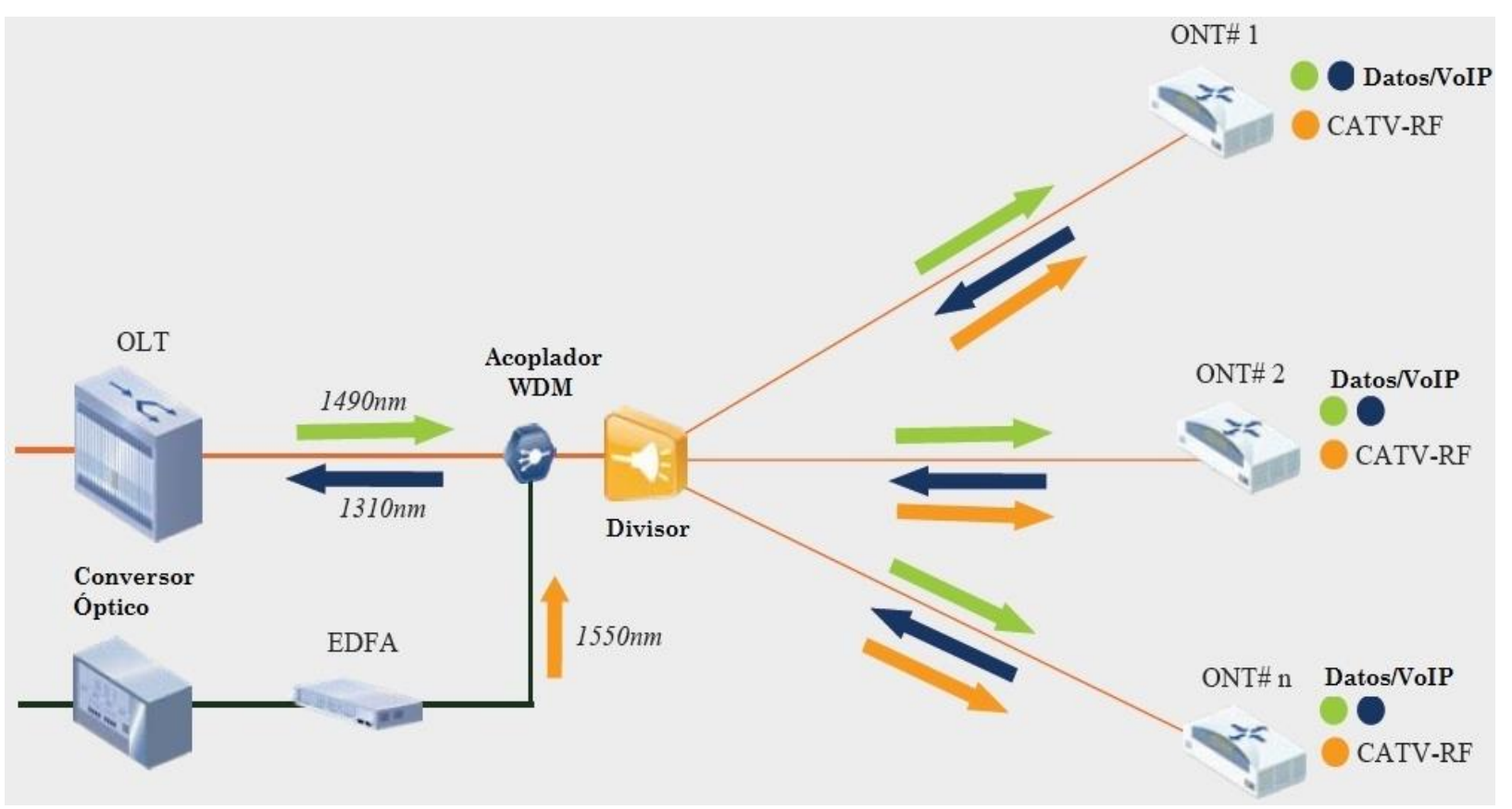

Fig. 1. Esquema de red FTTH-GPON. Fuente: [15]. 
Los sistemas de RoF transmiten señales de radio a través de la fibra óptica directamente hasta la BS. Cuando existen varias $\mathrm{BS}$, un dispositivo pasivo, conocido como splitter, divide la señal a las BS, como se observa en la Fig. 2.

Una de las ventajas más importantes de la tecnología RoF es la habilidad de concentrar lo más costoso del equipo de alta frecuencia en un lugar central $u$ oficina central (CO), lo cual permite la instalación del equipo restante en un lugar distante, debido a su sencillez, bajo peso, tamaño reducido y bajo consumo de potencia.

Entre otras ventajas adicionales se destaca el gran ancho de banda que proporciona la fibra en el transporte de señales de RF. Con los sistemas de RoF, las BS solo son utilizadas para realizar la conversión opto-eléctrica, por lo que su configuración es más simple e independiente del protocolo y del formato de modulación [3].

Hoy en día, la implementación y uso de servicios basados en IP se está llevando a cabo con conexiones de forma más inalámbrica, donde los usuarios finales por medio de sus teléfonos inteligentes acceden a Internet y usan algún tipo de servicio.

En la Fig. 3 se muestra una red heterogénea de banda ancha de próxima generación para diversos servicios.

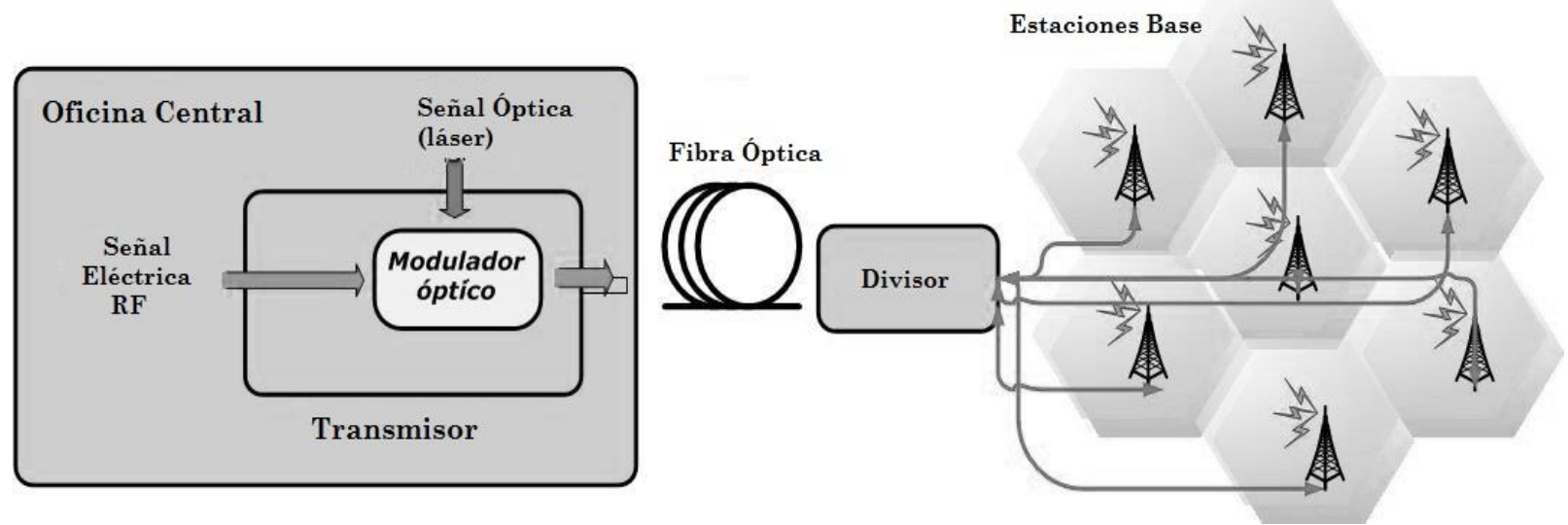

Fig. 2. Sistema RoF. Fuente: [3].

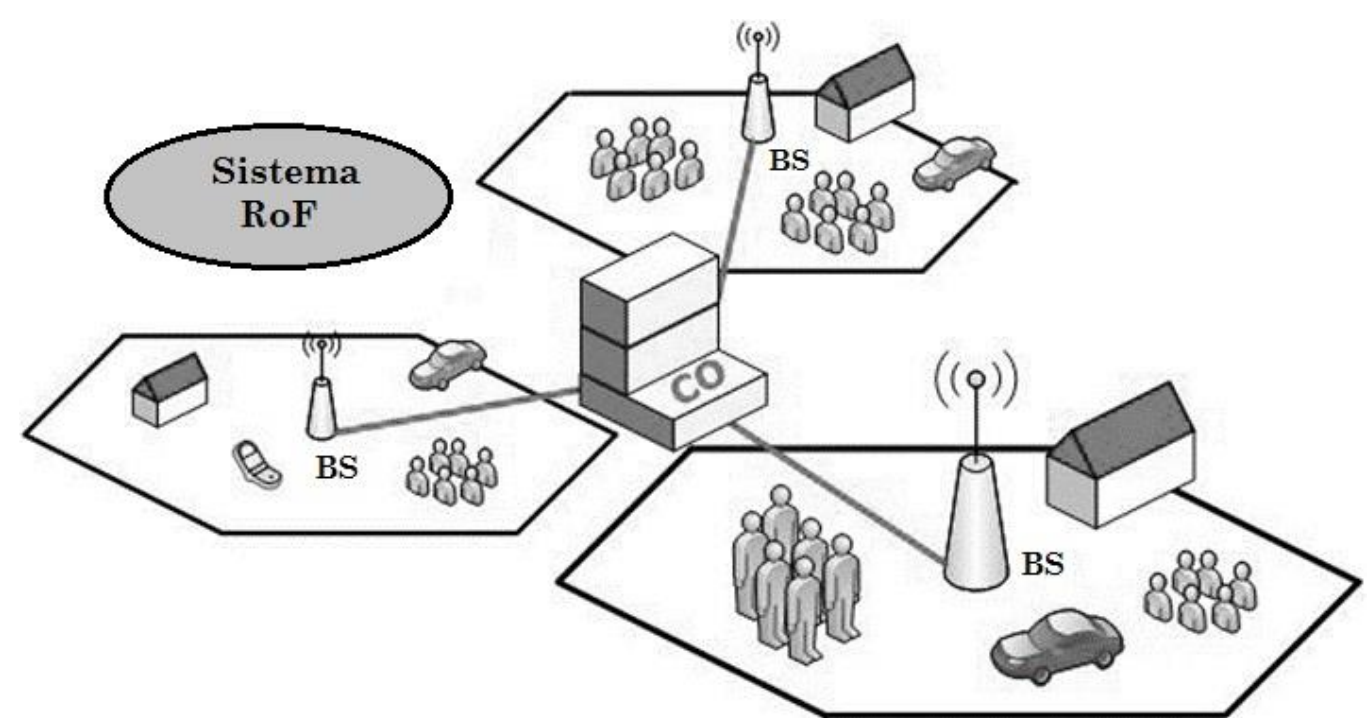

Fig. 3. Redes de acceso heterogéneas de banda ancha de próxima generación. Fuente: [3]. 
Los sistemas RoF están diseñados para desempeñar funciones de sistemas de radio, además de funciones de transporte y movilidad. Todas estas funciones incluyen modulación de datos, procesamiento de la señal y conversión de frecuencia.

El propósito principal de los sistemas RoF es la distribución de señales de banda ancha a las BS para acceso inalámbrico usando una red de acceso óptica. Por lo tanto, un sistema RoF consiste de cuatro elementos principales: el transmisor óptico, la red de acceso óptica, las BS y los receptores móviles o fijos [3].

Los sistemas RoF transmiten señales de radio a través de la fibra óptica desde un transmisor hasta una BS con el fin de llegar a los consumidores finales mediante un enlace de radio, como se observa en la Fig. 4.

Dentro del estado del arte, para los sistemas de RoF se han realizado múltiples investigaciones. Como se muestra en [17], los autores presentaron un software desarrollado sobre la plataforma LabVIEW de la casa National Instruments, el cual genera una librería denominada RoFSim (Simulador de RoF) basada en instrumentos virtuales (VI) para simular un sistema completo de transmisión de señales moduladas en el rango de radiofrecuencia sobre un esquema de comunicaciones ópticas RoF que incluyen: el láser transmisor, la fibra óptica y el fotodetector, en un ambiente completamente gráfico. Se presenta su estructura, su multicanalización y su análisis en el dominio del tiempo, de la frecuencia y del espectro óptico.

Por ejemplo, en [18] se describe la aplicación de los mezcladores optoelectrónicos auto-oscilantes basados en el uso de transmisiones pseudomórficos de alta movilidad electrónica sobre un sistema RoF, se trabajan con diferentes longitudes de onda, se muestran los resultados de la caracterización electro-óptica en un ambiente de total oscuridad como de luminosidad, y también se presentan para la banda de GSM.

Los principales resultados de [18] indican que se obtuvo gráficamente en oscuridad total el punto óptimo de operación del PHEMT (mezclador optoelectrónico auto-oscilante basado en el uso de transistores pseudomórficos de alta movilidad electrónica) en términos de la ganancia máxima del dispositivo, se mostró

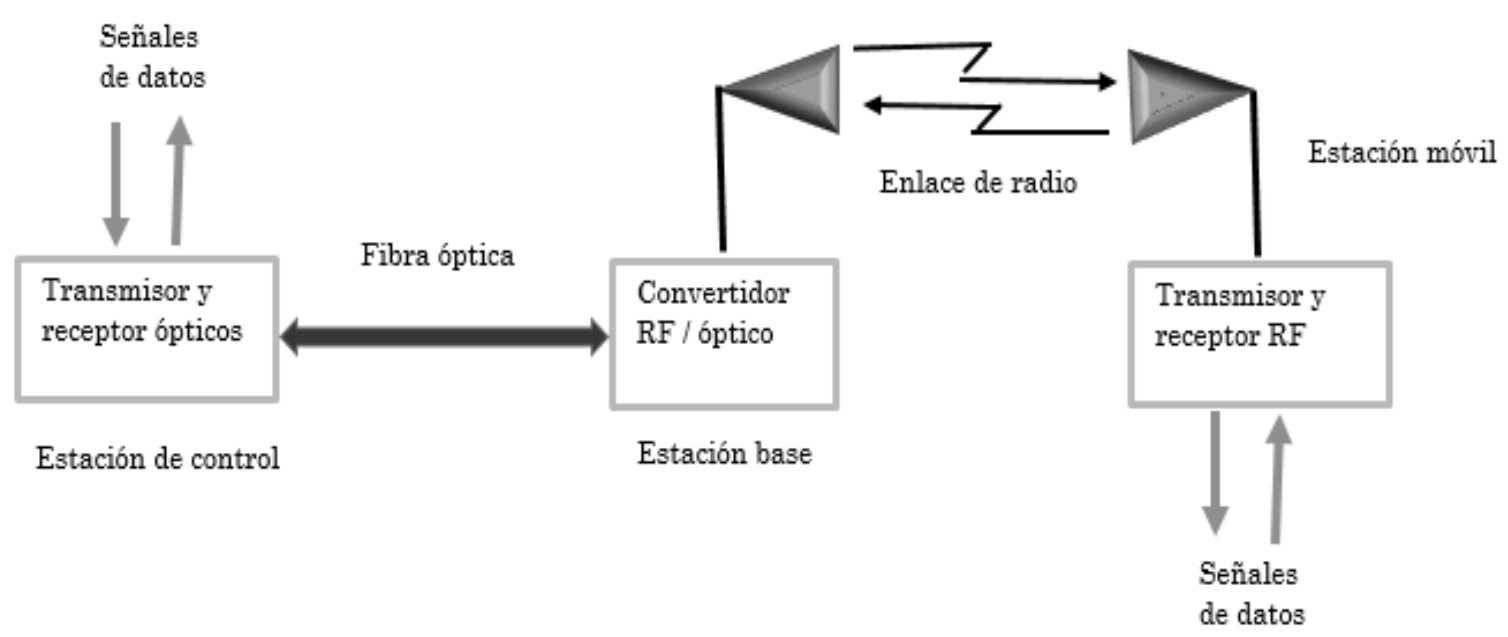

Fig. 4. Configuración de un sistema de comunicaciones RoF. Fuente: [16]. 


\section{Evaluación del desempeño físico de un sistema FTTH-GPON para servicios Quad Play}

después de la incorporación de un módulo RoF

también experimentalmente que en el PHEMT iluminado, la foto-corriente es dependiente del estado de polarización del haz de luz monocromática; también se concluye experimentalmente que el mezclador opto-electrónico auto-oscilante posee amplios rangos de mezclado dentro de los $5 \mathrm{GHz}$ de oscilación local, lo que permite su uso para sistemas RoF.

A su vez, en [19] se analizan las funcionalidades y prestaciones de las técnicas más utilizadas para generar señales de microondas/milimétricas, con el fin de identificar las más adecuadas que permitan generar señales en la banda de $60 \mathrm{GHz}$ para un sistema RoF. Asimismo, se analizan los efectos que introduce el canal en el transporte de la señal y finalmente se evalúa su rendimiento mediante simulaciones de sus figuras de mérito particularizadas para los esquemas planteados. Dentro de sus principales resultados cabe destacar que la modulación de fase supera a la modulación de intensidad aun cuando no esté configurada con sus parámetros de correcto funcionamiento. Además, con la escasa complejidad, el esquema que se propone permite utilizar señales de modulación sobre los $15 \mathrm{GHz}$, es decir, puede generar señales sobre los $60 \mathrm{GHz}$. Las simulaciones de las figuras de mérito corroboran dichos resultados de manera más exacta, aparte que, mediante ellas, permite de alguna forma pronosticar el comportamiento de la técnica con otros valores de configuración.

Adicionalmente, en [4] se hace un estudio comparativo de las técnicas de generación de señales para el transporte de información en sistemas de RoF usando técnicas de combinación óptica. En estos sistemas las portadoras de RF se transportan como subportadoras de canal óptico sobre un enlace en conexiones punto-punto o punto-multipunto. Entre los resultados más relevantes se muestra que los índices de modulación para los esquemas de brazo doble y serial presentan una fuerte dependencia entre sí, mientras que la configuración en paralelo permite una mayor flexibilidad en la selección de los índices de modulación.

En [5] se presenta un modelo analítico que describe los elementos involucrados en la generación de señales apropiadas en sistemas RoF para el transporte de información. El modelo tiene como base la definición del campo eléctrico y potencia a la salida del modulador óptico, que conjuga una señal modulada en banda base y una señal de RF en cualquier banda, donde resulta que, mediante el modelado de la función de campo, se encuentra que los índices de modulación presentan dependencia entre sí y se obtiene su valor óptimo a fin de garantizar una buena calidad para ambas señales en el receptor.

El autor de [20] analiza un sistema RoF de cuatro canales con fibra monomodo utilizando técnicas de multiplexación de subportadoras. Se consiguió un rango dinámico eléctrico libre de espurios de 51 $\mathrm{dB}$ que es suficiente para un alcance móvil de aproximadamente $100 \mathrm{~m}$. El uso de la multiplexación de subportadora simplifica el diseño del transceptor de radio y permite que el equipo de procesamiento complejo se ubique en la central local.

En [21], se muestra experimentalmente un sistema RoF de super banda ancha que transmite señales OFDM de 1 Gbps en portadoras de $\mathrm{mmW}$ de $40 \mathrm{GHz}$. Se logra más de $80 \mathrm{~km}$ vía fibra óptica monomodo estándar sin compensación de dispersión con menos de $0,5 \mathrm{~dB}$ de perdida de potencia.

En [22] la conversión óptica es mejor que la conversión eléctrica en enlaces simples de RoF de $60 \mathrm{GHz}$ basados en intensidad de modulación con detección directa (IMDD). Se prueba que la ecualización usada mejoró las prestaciones de ambos sistemas, permitiendo la transmisión libre de errores de 4 Gbps sobre $500 \mathrm{~m}$ de fibra estándar monomodo.

En la gran mayoría de trabajos relacionados con $\mathrm{RoF}$ existe un enfoque hacia el sistema RoF como tal y no se hace 
un estudio de cuál sería el impacto y/o desempeño al integrar un módulo RoF en una red FTTH-GPON Triple Play, lo que se constituye en el principal aporte del presente trabajo.

\section{METOdOLOGía DE DESARROLlo Y SIMULACIÓN}

Tomando como base la arquitectura FTTH-GPON y los sistemas RoF, se realizó un modelo de red con enfoque modular (orientado a componentes), el cual constó de elementos lógicos (nodos y enlaces) que representaron una primera abstracción de la red objetivo mostrando la interacción entre elementos (modelo conceptual).

Asimismo, se desarrolló un modelo físico, donde se representó cada elemento lógico por sus respectivos componentes físicos: terminal de línea óptica (OLT), medio óptico y terminal de nodo óptica (ONT) conocida también como unidad de red óptica (ONU), según los componentes disponibles en la herramienta de simulación OptSim, con lo cual se constituyó el respectivo modelo de simulación que fue evaluado mediante dicha herramienta definiendo y empleando para ello diferentes escenarios de simulación. Finalmente, se obtuvieron los resultados que fueron graficados y analizados para obtener una serie de conclusiones sobre el trabajo realizado.

OptSim permite evaluar el desempeño a nivel físico de la red FTTH-GPON al integrar el módulo RoF, con base en los parámetros OPM, mediante los escenarios de simulación propuestos.

Teniendo como referencia la metodología propuesta en [23], en la Fig. 5 se adapta y propone la metodología de desarrollo y simulación, con el fin de obtener los modelos lógicos (modelos conceptuales) y físicos (escenarios de simulación).

\subsection{Componente lógico o conceptual}

Todo el componente lógico está conformado por tres partes que son: la red FTTH-GPON Triple Play, el módulo RoF y por último la integración del módulo RoF a la red Triple Play para consolidar el sistema FTTH-GPON que soporte servicios Quad Play.

\subsection{Componente lógico (modelo conceptual) y físico (escenario de simulación) de la red FTTH-GPON Triple Play (sin el módulo RoF)}

En la Fig. 6 se muestra el modelo conceptual de la red FTTH-GPON Triple Play. Dicho modelo fue extraído con base en estudios realizados en [24], [25].

Como se puede apreciar, está conformado por diferentes nodos: en la OLT se tiene el servicio de datos/voz y el servicio de video, conformando de esta manera el nodo transmisor de la red FTTH-GPON Triple Play.

Los tres servicios se combinan y salen al medio de transmisión óptico (topología en árbol). Por último, está el nodo del receptor, ubicado en la ONT, el cual está conformado por el receptor de datos/voz y por el receptor de video.

En la Fig. 7 se muestra el componente físico o escenario de simulación de la red FTTH-GPON Triple Play. Este componente fue diseñado teniendo en cuenta el modelo lógico de la Fig. 6, especificando claramente que los componentes físicos fueron extraídos de OptSim, los cuales conforman el escenario con el fin de obtener los datos requeridos. La Tabla 1 muestra los parámetros de simulación utilizados. 
Evaluación del desempeño físico de un sistema FTTH-GPON para servicios Quad Play después de la incorporación de un módulo RoF

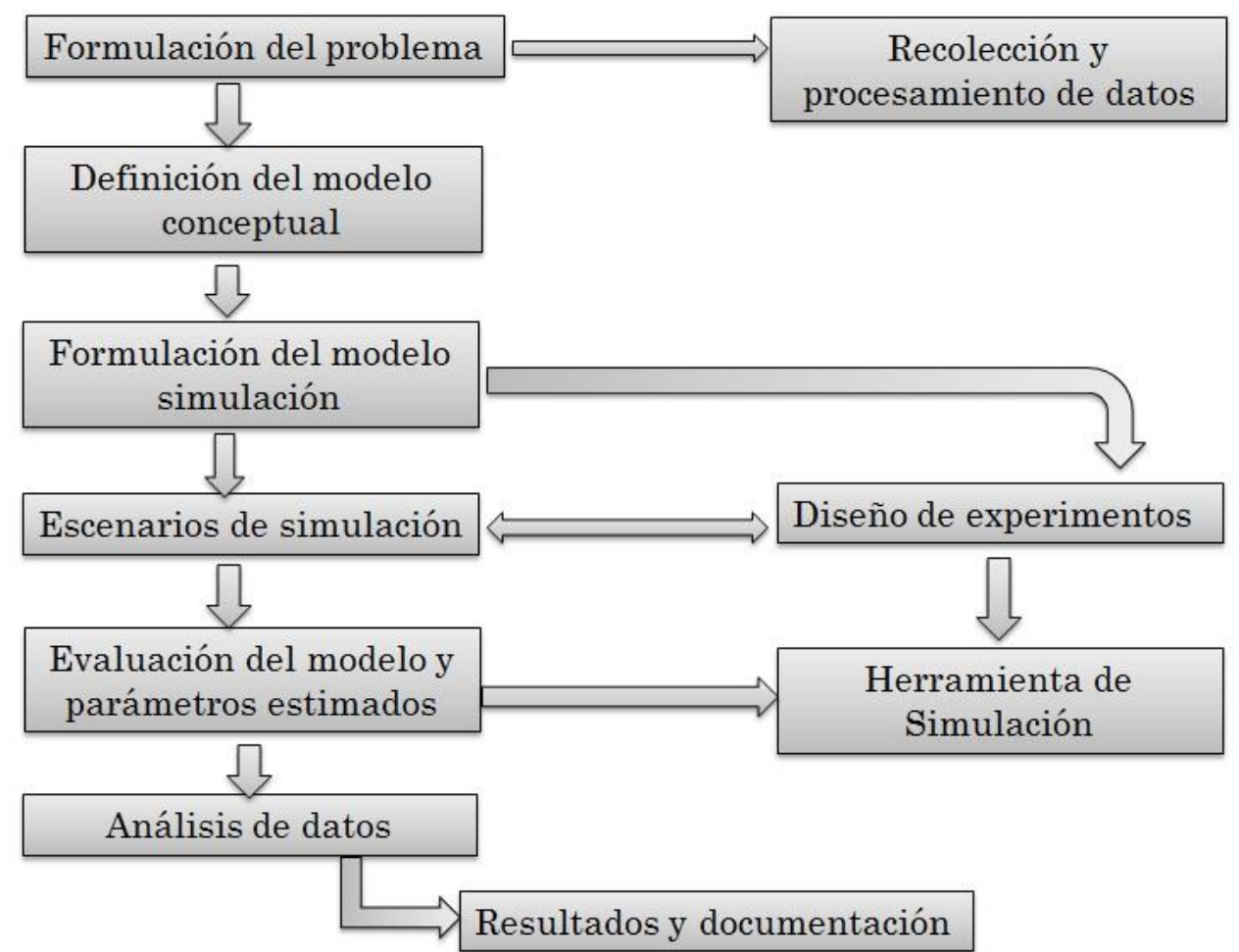

Fig. 5. Diseño de la simulación. Fuente: elaboración propia.

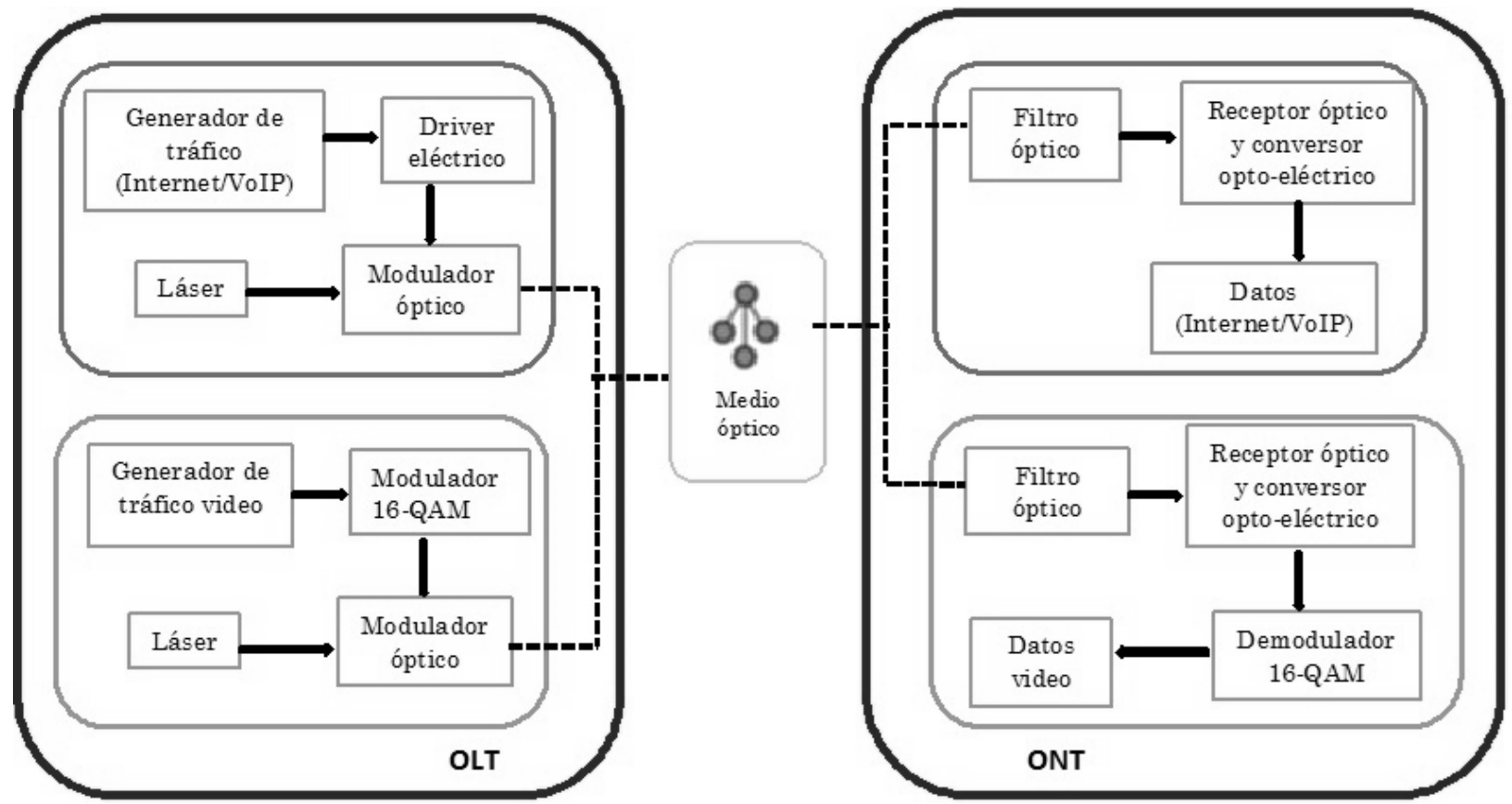

Fig. 6. Modelo conceptual de la red FTTH-GPON Triple Play (sin el módulo RoF). Fuente: [24]. 
Evaluación del desempeño físico de un sistema FTTH-GPON para servicios Quad Play después de la incorporación de un módulo RoF

\section{Oficina Central (OLT)}

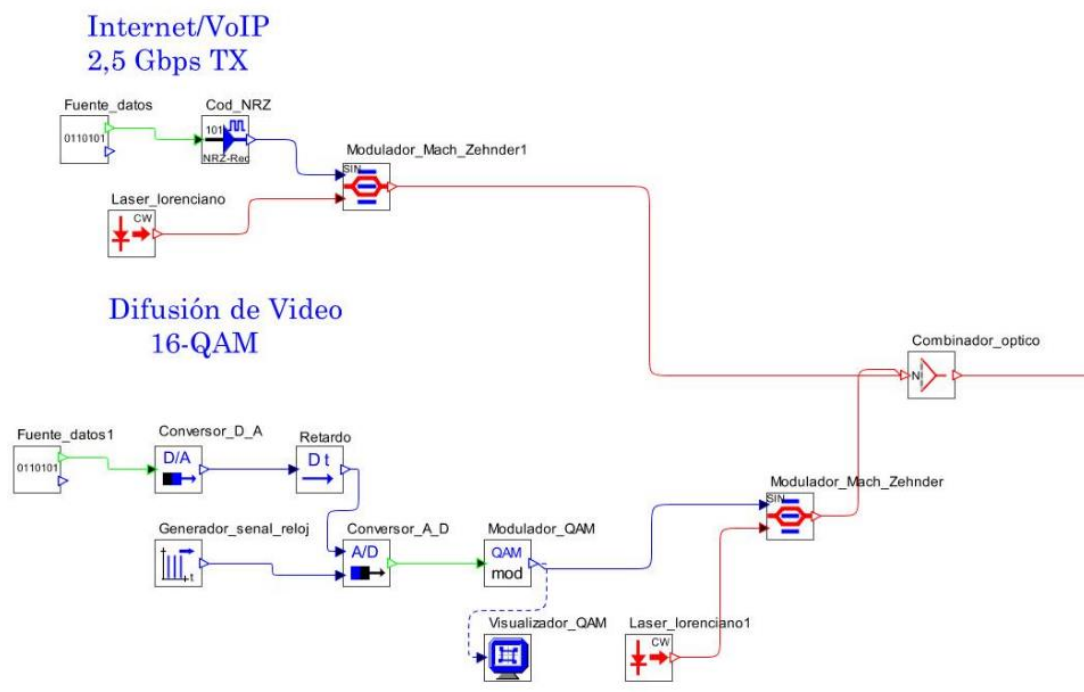

(a)

Enlace troncal $15 \mathrm{~km}$

\begin{abstract}
Enlace distribución
\end{abstract} $4,5 \mathrm{~km}$
Enlace acceso $0,3 \mathrm{~km}$

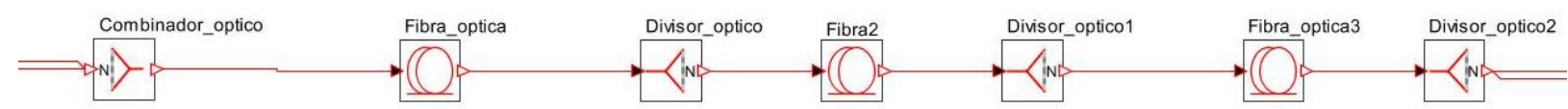

(b)

\section{Casa (ONT)}

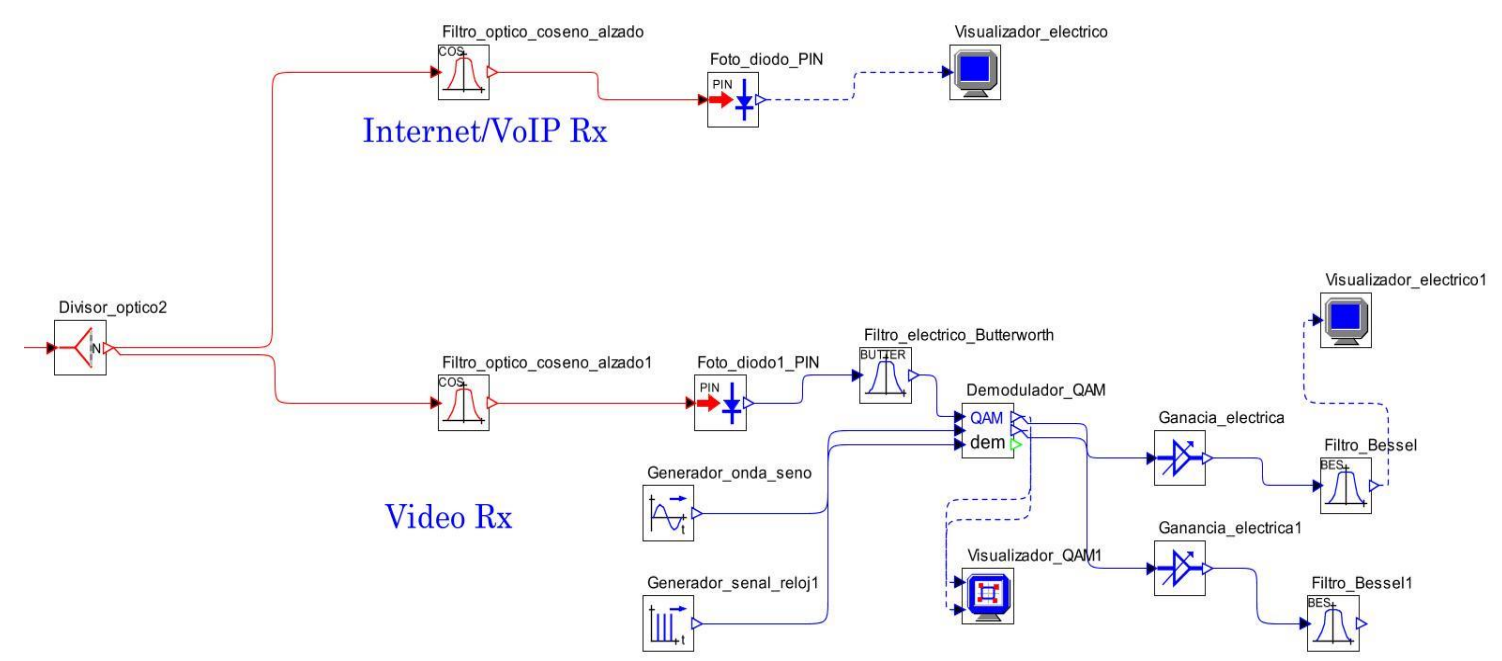

(c)

Fig. 7. Modelo físico de la red FTTH-GPON Triple Play (sin el módulo RoF) para una ONT. (a) Transmisor (OLT). (b) Medio óptico. (c) Receptor (ONT). Fuente: elaboración propia. 
Evaluación del desempeño físico de un sistema FTTH-GPON para servicios Quad Play después de la incorporación de un módulo RoF

Tabla 1. Parámetros técnicos establecidos para la simulación. Fuente: [24], [25].

\begin{tabular}{|c|c|}
\hline PARÁMETRO & VALOR \\
\hline \multicolumn{2}{|c|}{ Servicio de Internet y VoIP } \\
\hline Velocidad de transmisión & $2,5 \mathrm{Gbps}$ \\
\hline Longitud de onda & 1490 nm (Banda S) \\
\hline Potencia de transmisión & $0 \mathrm{dBm}$ \\
\hline Tipo de modulación óptica & Externa \\
\hline Sensibilidad de recepción & $-27 \mathrm{dBm}$ \\
\hline \multicolumn{2}{|c|}{ Servicio de CATV digital } \\
\hline Formato de modulación multinivel & 16-QAM \\
\hline Velocidad de transmisión & $0,8 \mathrm{Gbps}$ \\
\hline Portadora & $1000 \mathrm{MHz}$ \\
\hline Tipo de modulación óptica & Externa \\
\hline Potencia de transmisión & $8 \mathrm{dBm}$ \\
\hline Longitud de onda & 1550 nm (Banda C) \\
\hline Sensibilidad de recepción & $-16,3 \mathrm{dBm}$ \\
\hline \multicolumn{2}{|c|}{ Otros parámetros de la red } \\
\hline Láser & Onda continua \\
\hline Codificación de línea & NRZ \\
\hline Modulador & MZM \\
\hline Fibra óptica & $\begin{array}{l}\text { SMF-28 } \\
\text { CorningLEAF }\end{array}$ \\
\hline Atenuador & $1 \mathrm{~dB}$ \\
\hline Filtro eléctrico & Butterworth orden 16 \\
\hline Filtro óptico & Bessel orden 2 \\
\hline
\end{tabular}

\subsection{Componente lógico (modelo conceptual) y físico (escenario de simulación) del módulo RoF}

Teniendo cuenta lo expuesto en [16][18], [21], [26], se propone el componente lógico o modelo conceptual del módulo RoF, tanto en transmisión como en recepción, como se aprecia en la Fig. 8.

-Láser: fuente de luz con $0 \mathrm{dBm}$ de potencia, operando en la ventana de 1550 nm.

-Transmisor OFDM (señal radio): en este módulo se hace todo el tratamiento de la señal desde que sale de la fuente de datos hasta que llega al medio óptico. Aquí se realiza todo lo relacionado con codificación y modulación a nivel eléctrico; asimismo, se monta la señal ya modulada en 16-QAM sobre portadoras OFDM y se pasa a $\mathrm{RF}$ antes de entrar al modulador óptico.

-Modulador óptico: se utiliza la modulación externa ya que se comporta mucho mejor que la modulación directa a frecuencias mayores de $5 \mathrm{GHz}$. El modulador usado aquí es un EAM lineal.

-Medio óptico: este módulo tiene las mismas características y parámetros de la red FTTG-GPON Triple Play, es decir, está conformado por: combinadores ópticos, enlaces de fibra óptica troncal, de distribución y de acceso, y divisores ópticos.

-Filtro óptico: se encarga de dejar pasar la señal óptica de acuerdo con la frecuencia o longitud de onda de la portadora láser.

-Conversor opto-eléctrico: se encarga de la conversión del dominio óptico al dominio eléctrico. 
- Receptor OFDM (señal radio): en este módulo se realiza todo el tratamiento de la señal RF recuperada, es decir, se hace el proceso complementario a la transmisión, amplificando, filtrando y recuperando las portadoras OFDM con el fin de entregar los datos transmitidos al usuario final.

En la Fig. 9 se muestra el componente físico o escenario de simulación realizado en OptSim del componente lógico RoF, tanto del lado del transmisor (el cual está ubicado en la OLT de la red FTTH-GPON Triple Play), como del lado del receptor (ubicado en cada ONT de la red FTTHGPON Triple Play). La Fig. 10 muestra el diagrama de bloques OFDM, indicando de manera general el proceso llevado a cabo para el tratamiento de las señales en cada bloque.

En la Fig. 10 (a) se muestra un transmisor OFDM que se compone de los siguientes bloques:

-Fuente_datos: fuente de datos que genera una señal pseudo-aleatoria con una velocidad de transmisión de 10 Gbps.

-Datos_serial_paralelo: encargado de realizar la conversión serie a paralelo.

-Modulador_MQAM: encargado de generar los componentes en fase (I) y en cuadratura (Q) banda base del símbolo QAM.

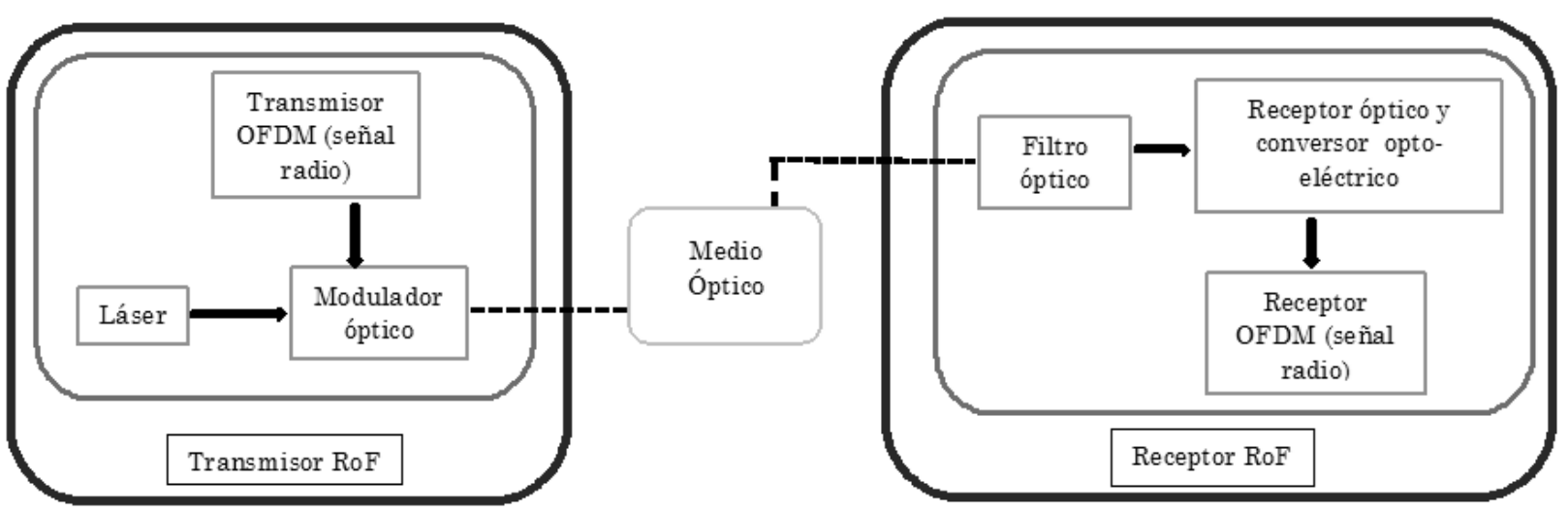

Fig. 8. Modelo conceptual del módulo RoF. Fuente: [16].

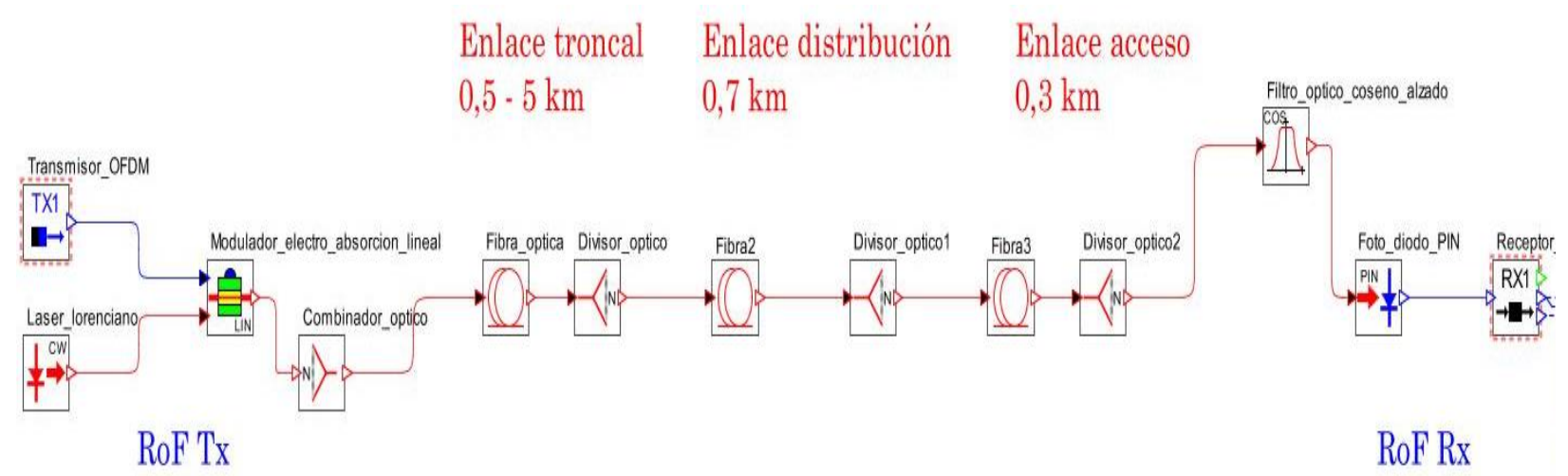

Fig. 9. Modelo físico del módulo RoF para una OLT y ONT Fuente: elaboración propia. 


\section{Transmisor OFDM}

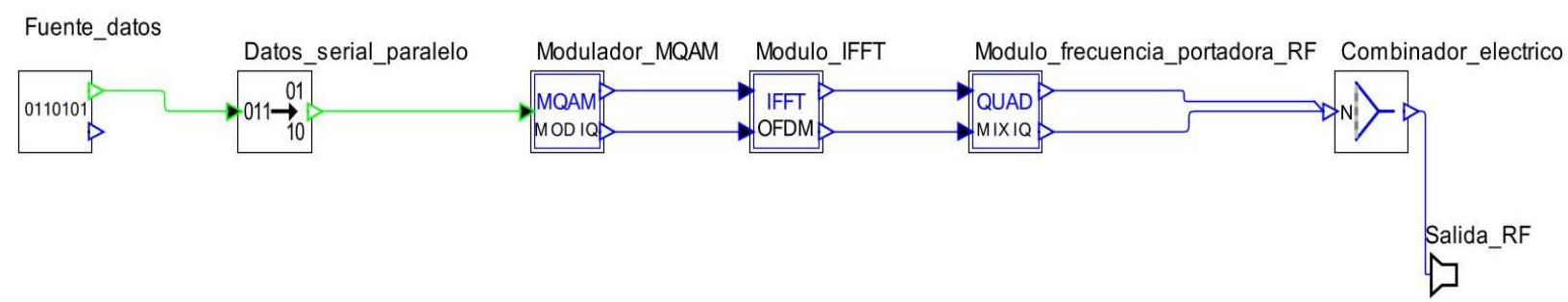

(a)

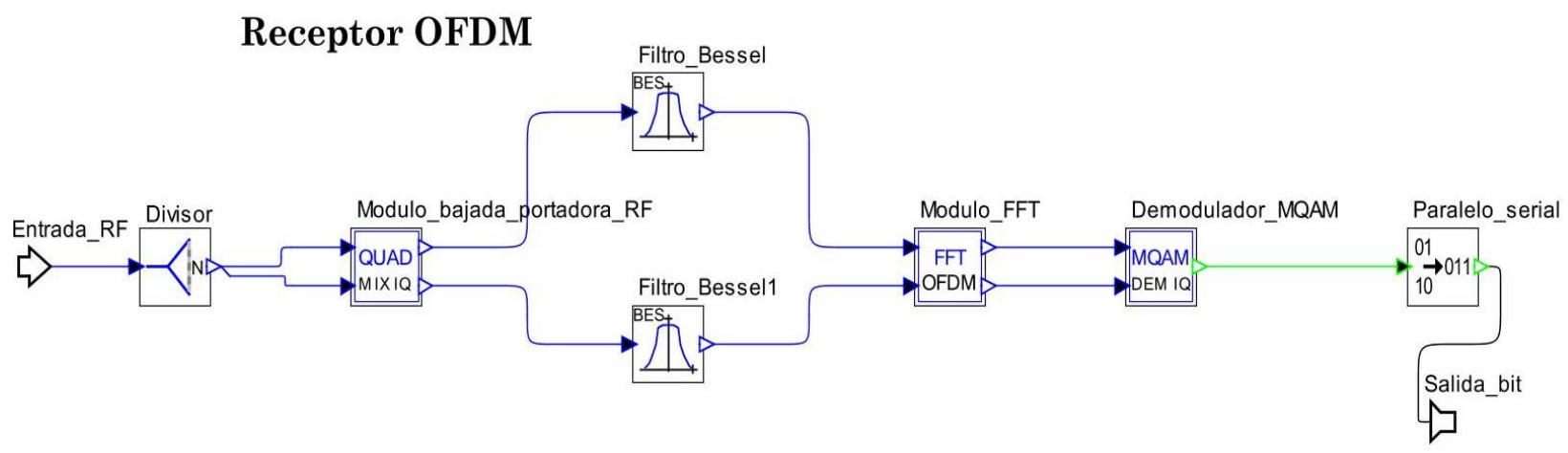

(b)

Fig. 10. Diagrama de bloques OFDM. (a) Transmisor. (b) Receptor Fuente: elaboración propia.

-Módulo_IFFT: calcula la IFFT sobre el símbolo QAM y obtiene el símbolo OFDM.

-Módulo_frecuencia_portadora_RF: encargado de montar la señal banda base en una portadora de alta frecuencia (10 $\mathrm{GHz}$ ).

-Combinador_eléctrico: combina las señales provenientes del bloque anterior para obtener la señal de RF.

Por su parte, en la Fig. 10 (b) se muestra el receptor OFDM compuesto por:

-Divisor: separa la señal de RF en dos réplicas.

-Módulo_bajada_portadora_RF:

encargado de bajar la señal OFDM modulada RF a banda base.
-Filtro_Besel: filtra la réplica uno de la señal centrada en dos veces la frecuencia portadora.

-Filtro_Besel1: filtra la réplica dos de la señal centrada en dos veces la frecuencia portadora.

-Módulo_FFT: calcula la FFT sobre el símbolo OFDM para recuperar el símbolo QAM.

-Demodulador_MQAM: recupera la señal lógica paralela del símbolo QAM.

-Paralelo_serial: encargado de realizar la conversión paralelo a serie y restaurar la secuencia binaria serial transmitida.

En la Tabla 2 se muestran los parámetros de configuración del módulo RoF. 
Evaluación del desempeño físico de un sistema FTTH-GPON para servicios Quad Play después de la incorporación de un módulo RoF

Tabla 2. Parámetros de configuración del módulo RoF

Fuente: elaboración propia.

\begin{tabular}{ll}
\hline \multicolumn{1}{c}{ PARÁMETRO } & \multicolumn{1}{c}{ VALOR } \\
\hline Velocidad de transmisión & \multicolumn{1}{c}{$10 \mathrm{Gbps}$} \\
Modulación 16-QAM & Módulo IFFT-OFDM \\
\hline Tasa de baudios & $2,5 \mathrm{Gbaud} / \mathrm{s}$ \\
Subportadoras & 8 \\
Prefijo cíclico & 0,25 \\
Retardo & 0 \\
Frecuencia RF & $10 \mathrm{GHz}$ \\
Frecuencia láser & $194 \mathrm{THz}$ \\
Potencia láser & $0 \mathrm{dBm}$ \\
& Otros parámetros de la red \\
\hline Láser & Onda continua \\
Codificación de línea & NRZ \\
Modulador & EAM lineal \\
Fibra óptica & SMF-28 \\
Atenuador & CorningLEAF \\
Filtro eléctrico & $1 \mathrm{~dB}$ \\
Filtro óptico & Butterworth orden 16 \\
\hline
\end{tabular}

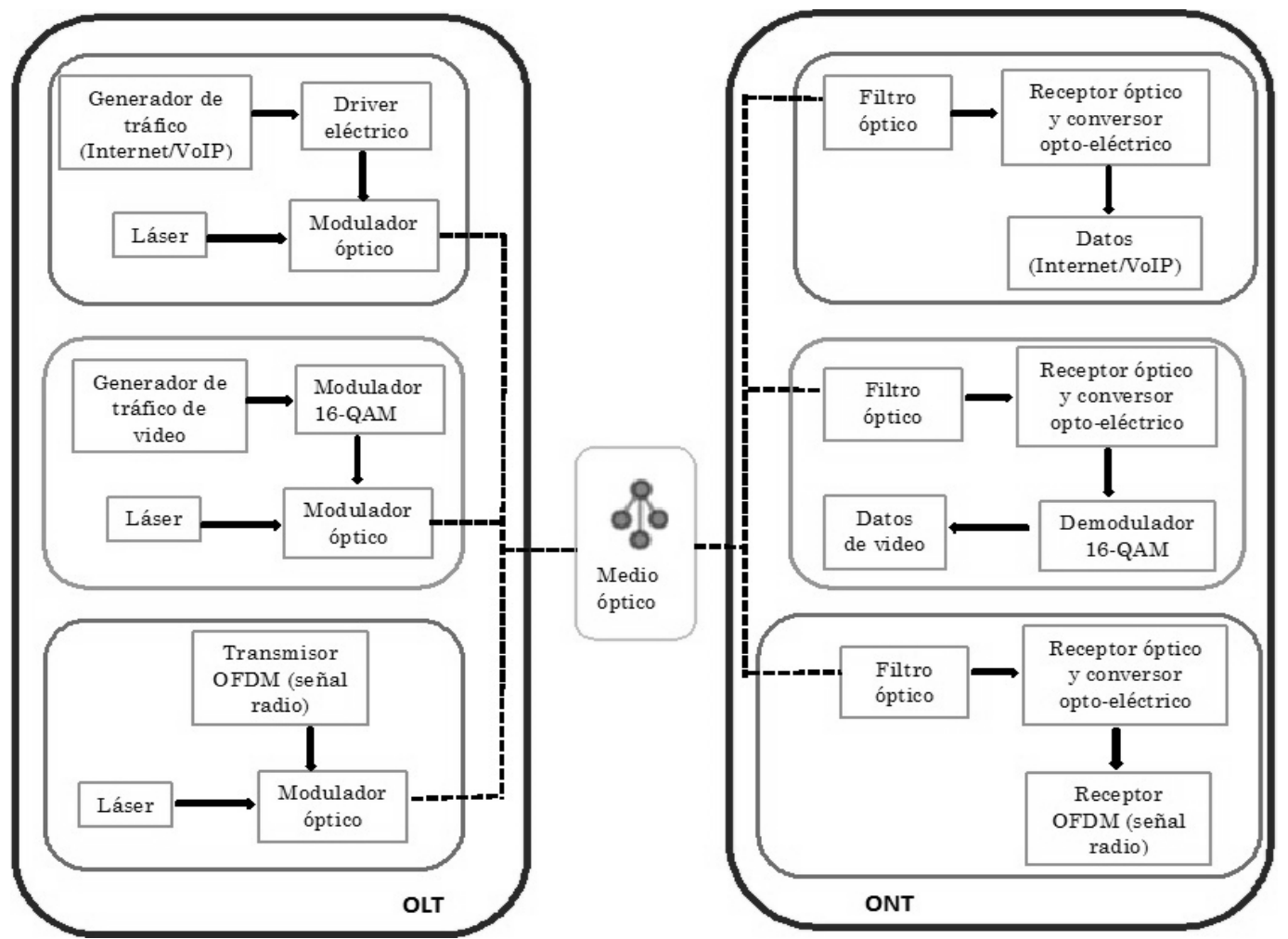

Fig. 11. Modelo conceptual de la red FTTH-GPON Quad Play (con el módulo RoF integrado)

Fuente: elaboración propia. 
Evaluación del desempeño físico de un sistema FTTH-GPON para servicios Quad Play después de la incorporación de un módulo RoF

\section{Oficina Central (OLT)}

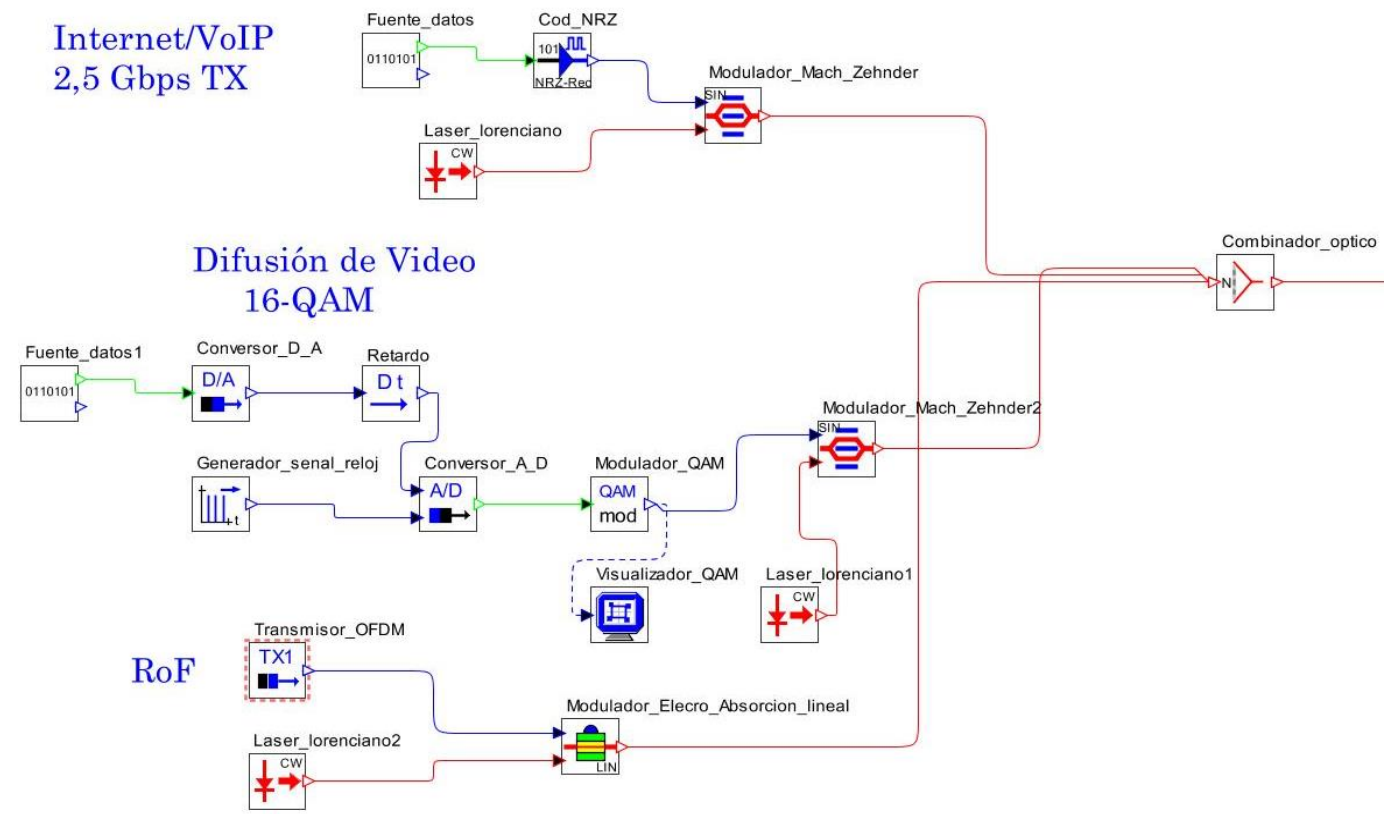

(a)

$\begin{array}{lll}\text { Enlace troncal } & \text { Enlace distribución } & \text { Enlace acceso } \\ 0,5-5 \mathrm{~km} & 0,7 \mathrm{~km} & 0,3 \mathrm{~km}\end{array}$

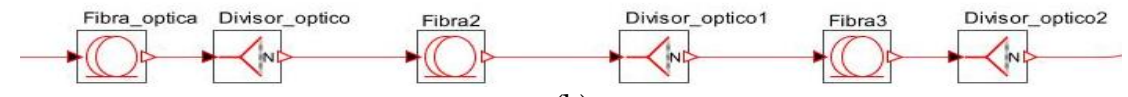

(b)



(c)

Fig. 12. Modelo físico de la red FTTH-GPON Quad Play (con el módulo RoF integrado) para una sola ONT

(a) Transmisor (OLT). (b) Medio óptico. (c) Receptor (ONT). Fuente: elaboración propia. 


\subsection{Componente lógico (modelo conceptual) y físico (escenario de simulación) de la red FTH-GPON Quad Play (con el módulo RoF integrado)}

En la Fig. 11 se muestra el componente lógico de la red FTTH GPON Quad Play (con el módulo RoF integrado) y en la Fig. 12 se muestra el componente físico de dicha red o escenario de simulación realizado en OptSim, manteniendo constantes los parámetros de configuración de las Tablas 1 y 2.

Ya establecida la metodología de desarrollo, se inició analizando el modelo de simulación para una red FTTH-GPON Triple Play (sin el módulo RoF), teniendo en cuenta algunas consideraciones de diseño y así poder lograr un buen desempeño de la red en cuanto a los parámetros OPM. En seguida, se analiza el módulo RoF en OptSim verificando que cumpla con las condiciones mínimas de calidad según lo estudiado en el estado del arte. Por último, se analiza el modelo de simulación final que es la red FTTH-GPON
Quad Play (con el módulo RoF integrado), analizando lo expuesto en [17]-[19], [21], [26].

\section{RESULTADOS Y DISCUSIÓN}

\subsection{Relación entre los parámetros de monitoreo EVM, SNR y BER}

La magnitud del vector de error (EVM) es una medida para evaluar la calidad de una señal modulada. Como se muestra en la Fig. 13, la EVM es un escalar que expresa la diferencia entre el valor del voltaje complejo esperado de un símbolo demodulado (I-Q de referencia) y el valor del símbolo recibido (I-Q medido) [27]. En el contexto de este trabajo, el valor I-Q de referencia es el medido en el diagrama de constelación back-to-back, mientras que el valor I-Q medido es el que se obtiene del diagrama de constelación en recepción, con lo cual fue posible calcular el valor de la EVM.

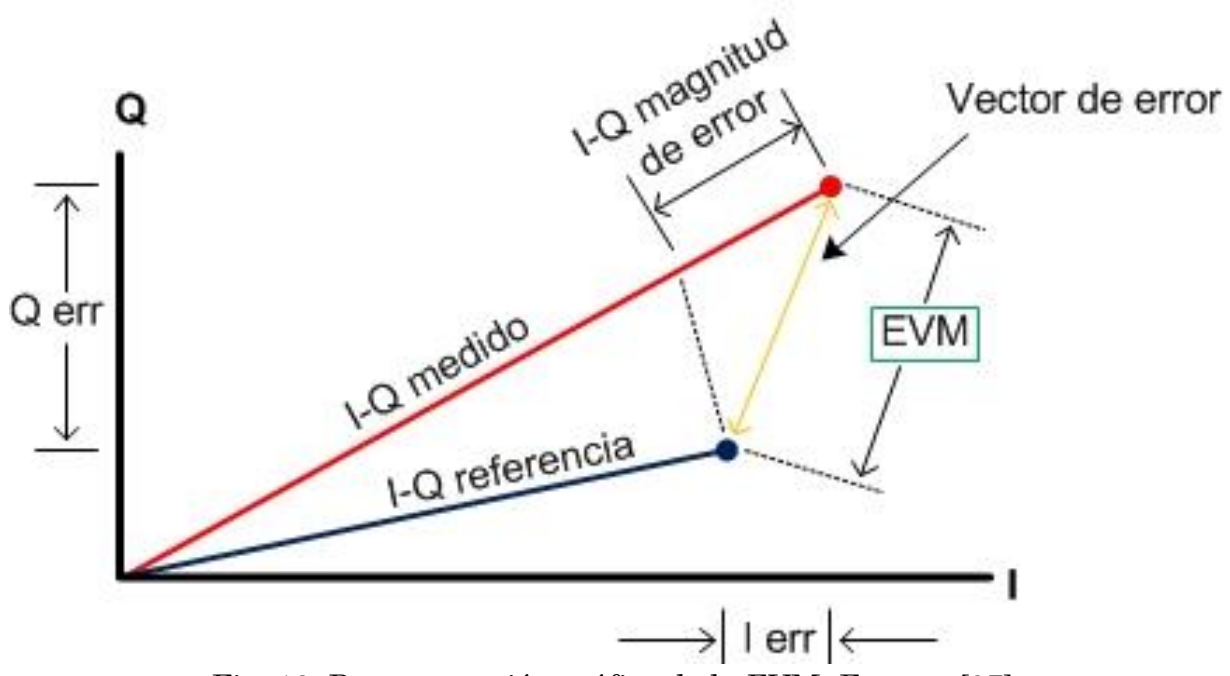

Fig. 13. Representación gráfica de la EVM. Fuente: [27]. 
La BER es el parámetro de desempeño más significativo de cualquier sistema de comunicación digital y depende de la SNR de la señal recibida, que a su vez está determinada por la potencia de la señal transmitida, la atenuación y dispersión del enlace y el ruido en recepción [6].

Por lo tanto, la BER en función de la SNR para un sistema M-QAM se describe en (1):

$$
B E R=\frac{2 \cdot\left(1-\frac{1}{\sqrt{M}}\right) \cdot \operatorname{erfc}\left(\sqrt{3 \cdot \frac{\text { SNR [lineal }]}{2 \cdot(M-1)}}\right)}{\log _{2} M}
$$

Donde, el valor de la SNR puede aproximarse en función de la EVM, como se muestra en (2):

$$
S N R[d B]=-20 \log \left(\frac{E V M}{100}\right)=10 \log (S N R[\text { lineal }])
$$

Evaluando (1) para la modulación 16QAM, la expresión de la BER es como lo estipula (3):

$$
B E R=\frac{3}{8} \cdot \operatorname{erfc}\left(\sqrt{\frac{S N R[\text { lineal }]}{10}}\right)
$$

Utilizando el anterior procedimiento, y usando OptSim, se llevó a cabo el cálculo de la BER para el módulo RoF en el presente trabajo.

\subsection{Análisis de resultados}

Para el análisis de los resultados se consideraron algunos aspectos en los diferentes modelos de simulación:

-Tráfico: permanente y no variable (secuencias pseudoaleatorias).

-Potencia del láser constante.

-Multiplexación por división de longitud de onda (WDM), multiplexores y demultiplexores no ideales.

-Parámetros OPM a evaluar: potencia de recepción óptica (PRxo), EVM, SNR, BER, factor $Q$.
-Parámetros variables: número de ONT y distancia.

-Fibra óptica monomodo: la fibra óptica de dispersión positiva estándar ITU-T G.652 llamada SMF-28 en OptSim y la fibra de dispersión negativa ITU-T G.655 llamada CorningLEAF en OptSim.

Ambas se usan con longitudes de onda desde $1490 \mathrm{~nm}$ a $1550 \mathrm{~nm}$. Los valores escogidos de atenuación y de dispersión para las fibras utilizadas en la simulación corresponden a datos de referencia y a datos reales, que se pueden encontrar en las recomendaciones ITU-T (G.652 y G.655) y en las hojas de datos del proveedor de fibra Corning.

Los servicios Triple Play se configuraron con las características actuales usadas en las redes FTTH-GPON (ver Tabla 1). Para el servicio de datos/voz (Internet/VoIP) se utilizó una portadora de $1490 \mathrm{~nm}$ de longitud de onda con $0 \mathrm{dBm}$ de potencia a una velocidad de 2,5 Gbps.

Para el servicio de video (CATV digital) se utilizó modulación 16-QAM y una portadora de $1550 \mathrm{~nm}$ de longitud de onda con $8 \mathrm{dBm}$ de potencia a una velocidad de 0,8 Gbps. Con el fin de soportar servicios Quad Play (ver Tabla 2), para el servicio de Internet móvil, se propuso un transmisor/receptor OFDM (16-QAM, RF $10 \mathrm{GHz}$ ) con un plan de frecuencias (según la recomendación ITU-T G.694.1 donde se especifica dicho plan para DWDM) de 1 a 64 canales desde 193,6 a 199,9 $\mathrm{THz}$ equivalentes a longitudes de onda desde 1548,5 hasta $1499,7 \mathrm{~nm}$ con espaciamiento de $0,1 \mathrm{THz}$ (aproximadamente 0,75-0,8 nm) con $0 \mathrm{dBm}$ de potencia a una velocidad de 10 Gbps.

Los resultados y discusión de los escenarios planteados, se realizaron en tres partes: la primera es el análisis del módulo RoF, la segunda es el impacto cuando se integra el módulo RoF a la red FTTH-GPON y la tercera son los resultados de las pruebas realizadas variando el número de ONT en la red FTTH-GPON Quad Play con distancia 
constante y variable. Cabe anotar que solamente se consideró el análisis en el enlace descendente, es decir, desde la OLT hasta la ONT.

\subsection{Análisis de la red FTH-GPON Triple Play de referencia}

Es importante mencionar que los servicios Triple Play en la red FTTHGPON tienen un buen desempeño hasta 20 $\mathrm{km}$ usando fibra SMF-28 (BER del orden de $10^{-40}$ para el servicio de datos/voz y BER del orden de $10^{-7}$ para el servicio de CATV digital).
En la Fig. 14 se muestra los parámetros de desempeño de la red FTTH-GPON Triple Play. Por un lado, en la Fig. 14 (a) se puede observar el diagrama del ojo de la señal de datos/voz, que para estos servicios corresponde a un excelente desempeño para una distancia de $19,8 \mathrm{~km}$ pues la BER es de $10^{-40}$ (factor $\mathrm{Q}=33,822 \mathrm{~dB}$ ).

Por su parte, en la Fig. 14 (b) se aprecia el diagrama del ojo de la señal de video, que para este servicio corresponde también a un excelente desempeño para una distancia de $19,8 \mathrm{~km}$ pues la BER es de $5,655 \quad \mathrm{x} \quad 10^{-7} \quad$ (Factor $\left.\mathrm{Q}=13,451 \mathrm{~dB}\right)$.

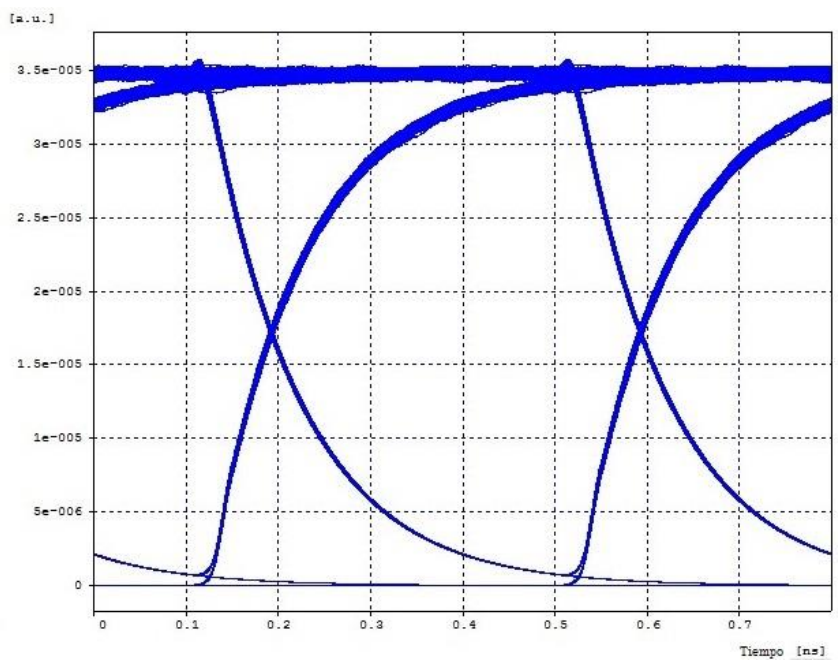

(a)



(b)

Fig. 14. Parámetros de desempeño de la red FTTH-GPON Triple Play para una distancia de 19,8 km (a) Diagrama del ojo de la señal de datos/voz. (b) Diagrama del ojo de la señal de video Fuente: elaboración propia. 


\subsection{Análisis del módulo RoF}

Teniendo en cuenta que el contexto de este trabajo se enfoca en redes FTTHGPON cuya distancia máxima es de $20 \mathrm{~km}$, ofreciendo actualmente servicios Triple Play como solución de acceso de "último kilómetro", con el fin de proveer un cuarto servicio de Internet móvil (Quad Play), fue necesario rediseñar el módulo RoF propuesto por defecto en OptSim porque su desempeño solo permitía alcanzar $300 \mathrm{~m}$ de distancia. Para ello se cambió el tipo de modulador óptico, es decir, el modulador de fase (MZM) lineal por el modulador EAM lineal. Según [16], [18], [19], [21], [26], el modulador EAM presenta un mejor desempeño que el de fase cuando se requiere alcanzar mayor distancia. De esta manera, cuando se usó la fibra SMF-28, se logró un alcance máximo de $1,250 \mathrm{~km}$, en comparación con la fibra CorningLEAF donde se obtuvo un alcance de $5,860 \mathrm{~km}$.

En la Fig. 15 se observa una señal OFDM a $10 \mathrm{GHz}$ en el dominio de la frecuencia. La Fig. 15 (a) detalla el espectro de la señal en el transmisor y la Fig. 15 (b) lo hace en el receptor. Para un alcance máximo de $5,860 \mathrm{~km}$, se ha atenuado considerablemente (aproximadamente $100 \mathrm{~dB}$ ).

Afortunadamente, después de que la señal es tratada con la FFT, dicha señal tiene una ganancia suficiente $(100 \mathrm{~dB})$ para contrarrestar la atenuación, lo que permite recuperar la señal original en el receptor de manera correcta. Para corroborar la recuperación exitosa de la información transmitida, en la Fig. 16 se puede apreciar el diagrama de constelación (en fase y cuadratura) de la señal de radio.
Mediante las Fig. 16 (a) y (b), se realiza la medida y se compara entre una distancia de $0 \mathrm{~km}$ (configuración back-toback) y una distancia de $5,860 \mathrm{~km}$, evidenciando que, a pesar de haber una rotación en el diagrama de constelación debido a la falta de coincidencia de fase entre la señal recibida y la señal de la portadora de referencia, la información es recuperada satisfactoriamente. Con el fin de estimar el límite inferior de desempeño, es decir, un escenario del peor de los casos, no se corrigió el desfase del diagrama de constelación en recepción.

El módulo RoF propuesto funciona hasta una distancia de $5,860 \mathrm{~km}$. Por encima de esta distancia, la EVM es mayor a 14,877 \% y la correspondiente BER está por encima de la máxima permitida $\left(10^{-3}\right.$ para la señal radio según lo sugerido en [16]).

De acuerdo con los resultados de [6], [7], el módulo RoF diseñado en el presente trabajo está limitado en su desempeño, posiblemente debido a varios factores, tales como:

-Ruido de fotodetección.

-Las características no lineales del modulador en el sistema RoF provocan distorsiones durante el proceso de conversión eléctrico-óptico-eléctrico, degradando la calidad general de la señal.

-Degradación del factor $Q$ en tasas superiores a 1 Gbps.

-Las distorsiones aumentan proporcionalmente a la velocidad de transmisión.

-La distorsión de intermodulación se extiende por todo el espectro. 
Evaluación del desempeño físico de un sistema FTTH-GPON para servicios Quad Play después de la incorporación de un módulo RoF



(a)



(b)

Fig. 15. Señal OFDM a $10 \mathrm{GHz}$ en el dominio de la frecuencia. (a) En el transmisor. (b) En el receptor Fuente: elaboración propia. 


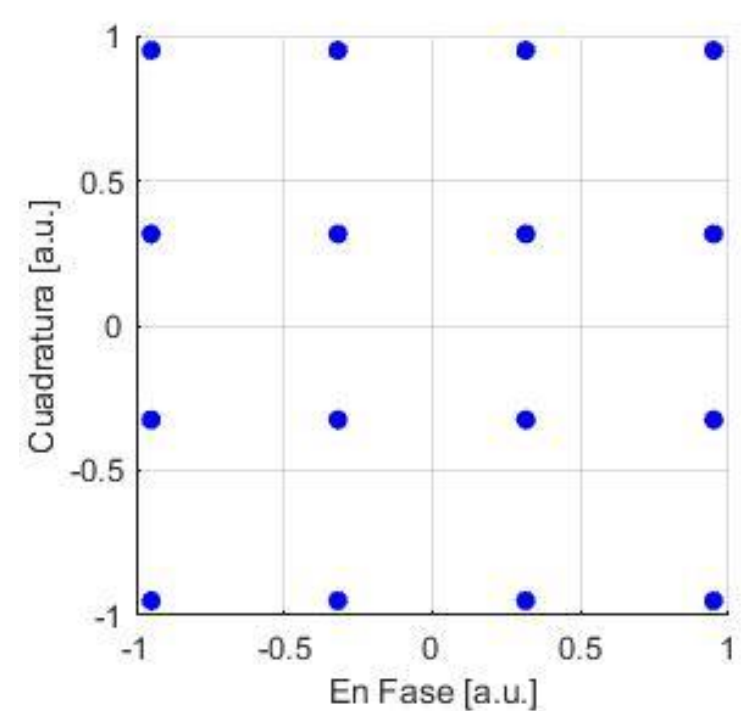

(a)

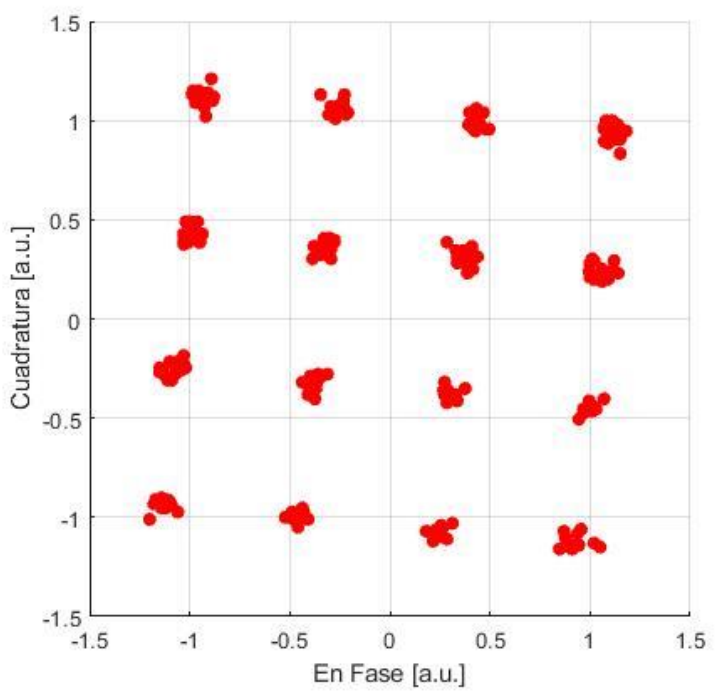

(b)

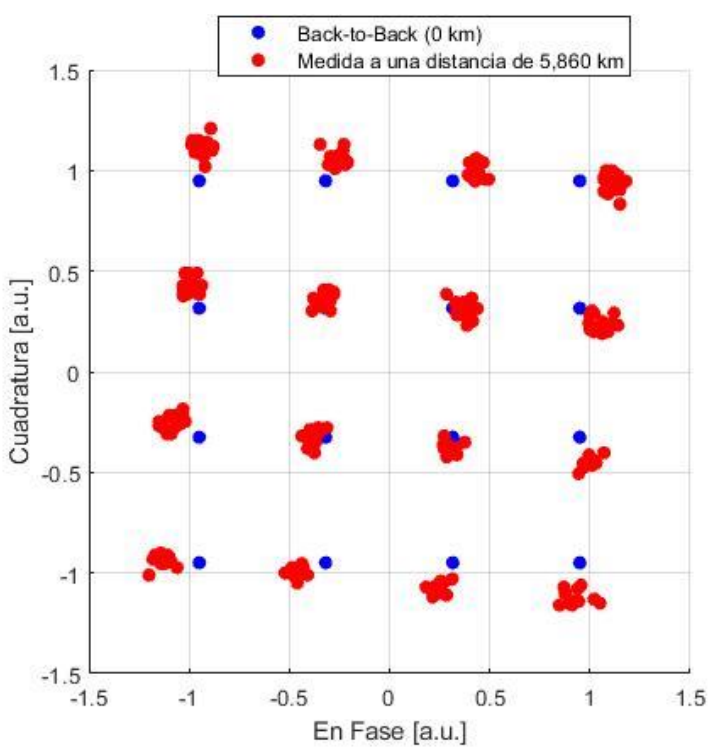

(c)

Fig. 16. Diagrama de constelación (en fase y cuadratura) de la señal radio. (a) Back-to-back (0 km). (b) Medida a una distancia de 5,860 km. c) Superpuesto: ideal vs recibido. Fuente: elaboración propia.

\subsection{Impacto cuando se integra el módulo RoF a la red FTH-GPON Triple Play}

En el análisis realizado al módulo RoF independiente, se obtuvo una distancia máxima de $5,860 \mathrm{~km}$ desde el transmisor hasta el receptor, correspondiente a una EVM del 14,877 \% representando una BER máxima de $10^{-3}$. Cuando se integró este módulo RoF a la red FTTH-GPON Triple Play, la EVM en el receptor RoF disminuyó a $14,819 \%$, lo cual mejoró la BER en una pequeña cantidad. Esta mejora de parámetro permitió obtener una ganancia en la distancia entre la OLT y la ONT de la red FTTH-GPON Quad Play ya consolidada, pasando de $5,860 \mathrm{~km}$ a 5,887 $\mathrm{km}(17 \mathrm{~m})$. Por lo anterior, se fijó la nueva distancia para la red FTTH-GPON con el módulo RoF integrado en $5,887 \mathrm{~km}$.

En cuanto a los otros servicios Triple Play (datos/voz y video) su desempeño no varió con respecto al análisis realizado anteriormente puesto que su alcance es hasta los $20 \mathrm{~km}$. 
En la Fig. 17 se puede ver la variación del diagrama del ojo con la distancia (cerrándose proporcionalmente) para la señal de datos/voz medida en el receptor.

Asimismo, en la Fig. 18 es apreciable la variación del diagrama del ojo con la distancia (cerrándose proporcionalmente) para la señal de video medida en el receptor. De acuerdo con lo anterior, se corroboró que los servicios Triple Play en la red FTTH-GPON tienen un buen desempeño hasta $20 \mathrm{~km}$ (ver Fig. 14), y, por lo tanto, el único servicio que está limitado para una distancia de $5,877 \mathrm{~km}$ es el de Internet móvil. De esta manera, es indispensable monitorear dicho servicio cuando se aumente el número de portadoras de radio. Además, la Fig. 19 deja ver la variación del espectro de frecuencias con la distancia en el canal óptico para los cuatro servicios de la red FTTH-GPON, apreciando como aumenta la atenuación proporcionalmente con la distancia.

Para las Fig. 17-19, la distancia está en función de los colores usados. La convención usada va de arriba hacia abajo. El primero es verde oscuro $(1 \mathrm{~km})$, el segundo es azul claro $(2 \mathrm{~km})$, el tercero es verde claro $(3 \mathrm{~km})$, el cuarto es morado (4 $\mathrm{km})$, el quinto es azul oscuro $(5 \mathrm{~km})$ y el sexto es café $(5,877 \mathrm{~km})$.

La Fig. 20 muestra las señales Quad Play (datos/voz, video y radio) en el canal óptico. A través de las Fig. 21-23 se muestran los resultados gráficos del comportamiento del módulo RoF ya integrado a la red FTTH-GPON, teniendo en cuenta los parámetros OPM a analizar, donde la PRxo es inversamente proporcional a la distancia entre la OLT y la ONT, y consecuentemente, la EVM y la BER son directamente proporcionales a dicha distancia. Los resultados permiten corroborar que se tiene un buen desempeño de dicho servicio para una distancia menor a $5,877 \mathrm{~km}$, evidenciando que el módulo RoF cumple con las condiciones establecidas en [16]-[19], [21], [26].

Con el fin de consolidar todos los resultados de las distintas pruebas hechas en los escenarios de simulación, la Tabla 3 muestra un resumen sobre la comparación del desempeño de los servicios de la red FTTH-GPON Triple Play versus Quad Play para una sola ONT de referencia.

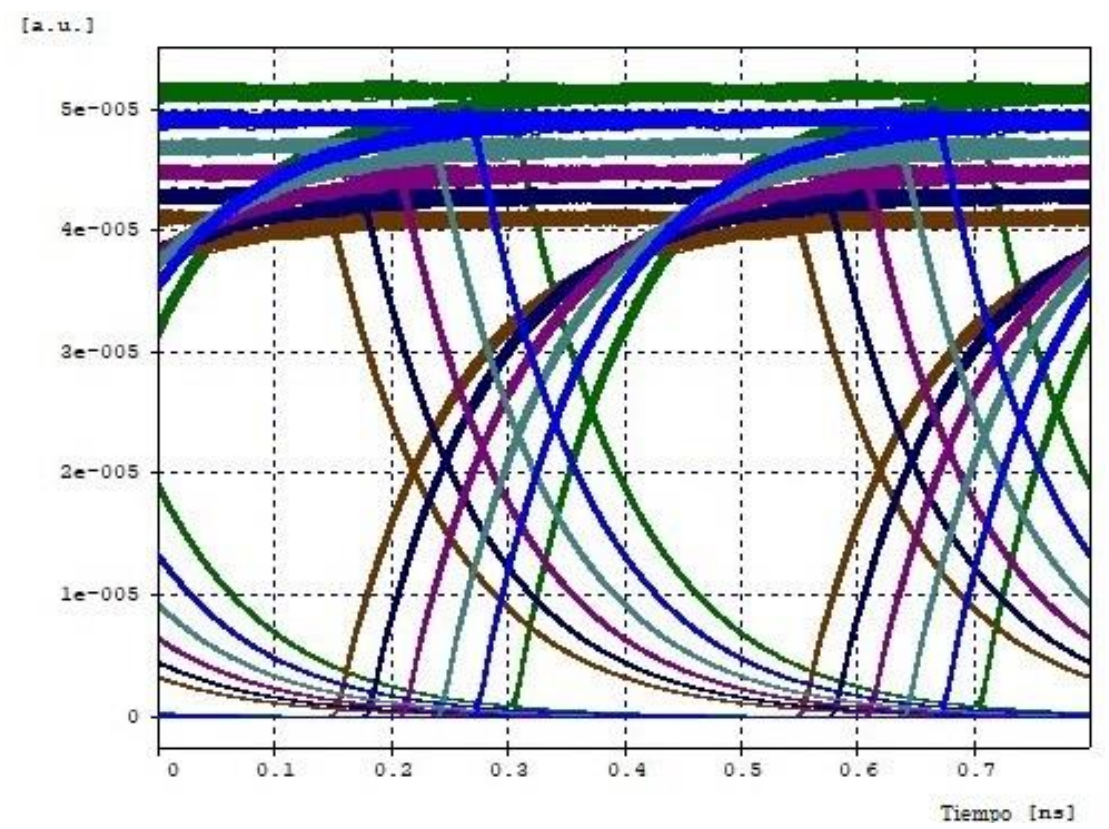

Fig. 17. Variación del diagrama del ojo con la distancia para la señal de datos/voz medida en el receptor Fuente: elaboración propia. 
Evaluación del desempeño físico de un sistema FTTH-GPON para servicios Quad Play después de la incorporación de un módulo RoF

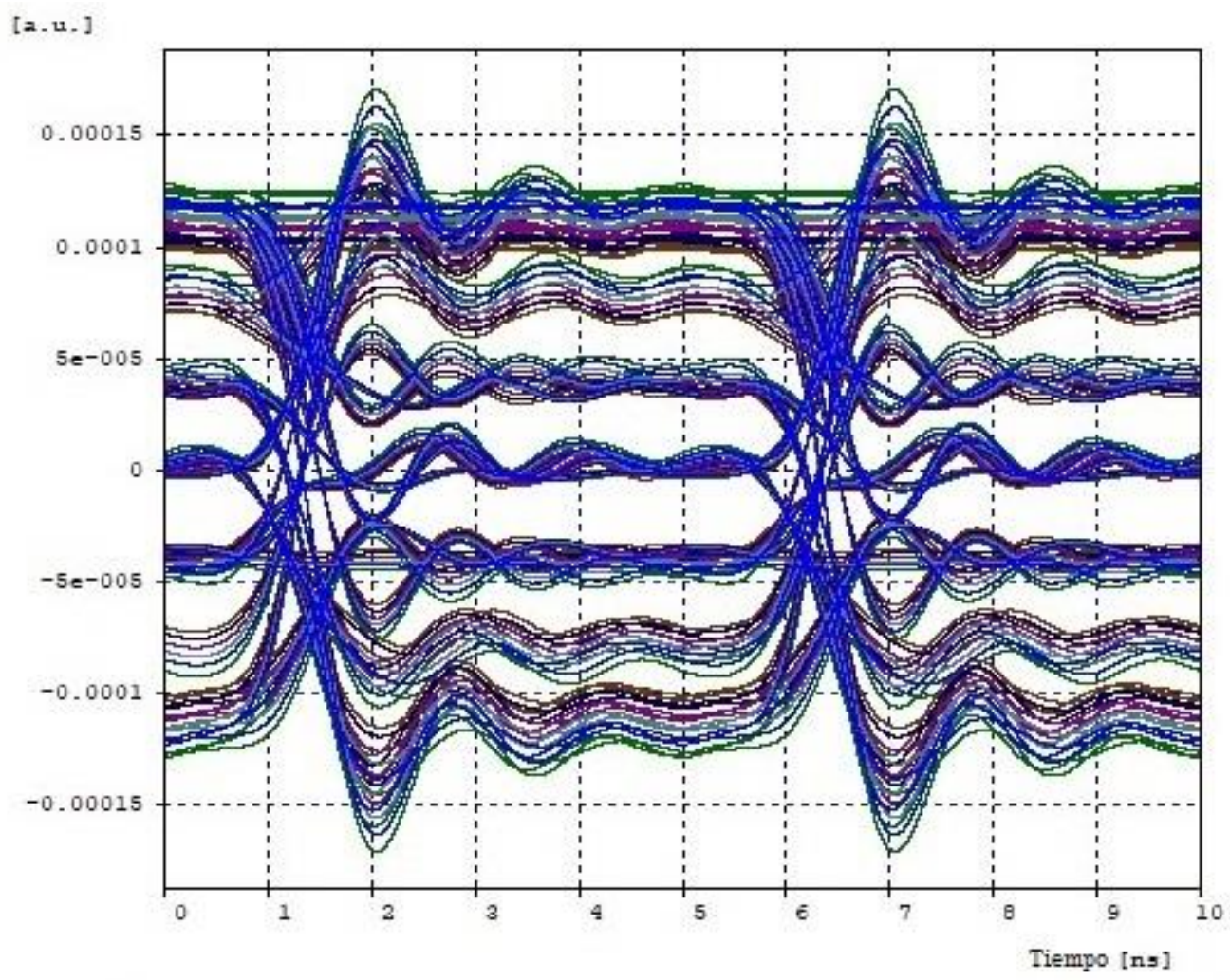

Fig. 18. Variación del diagrama del ojo con la distancia para la señal de video medida en el receptor Fuente: elaboración propia.



Fig. 19. Variación del espectro de frecuencias con la distancia en el canal óptico para los cuatro servicios de la red FTTH-GPON. Fuente: elaboración propia. 
Evaluación del desempeño físico de un sistema FTTH-GPON para servicios Quad Play después de la incorporación de un módulo RoF

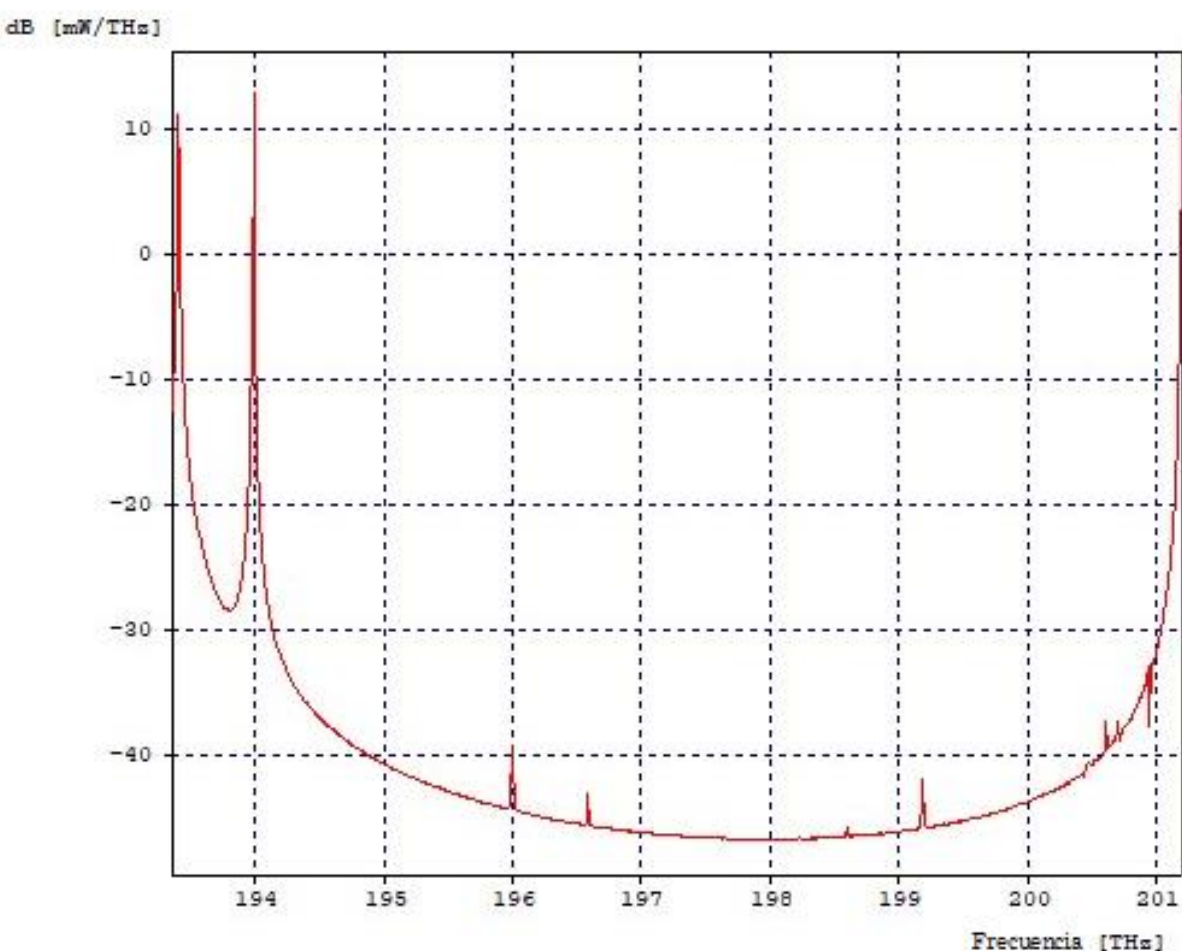

Fig. 20. Señales Quad Play (datos/voz, video y radio) en el canal óptico Fuente: elaboración propia.

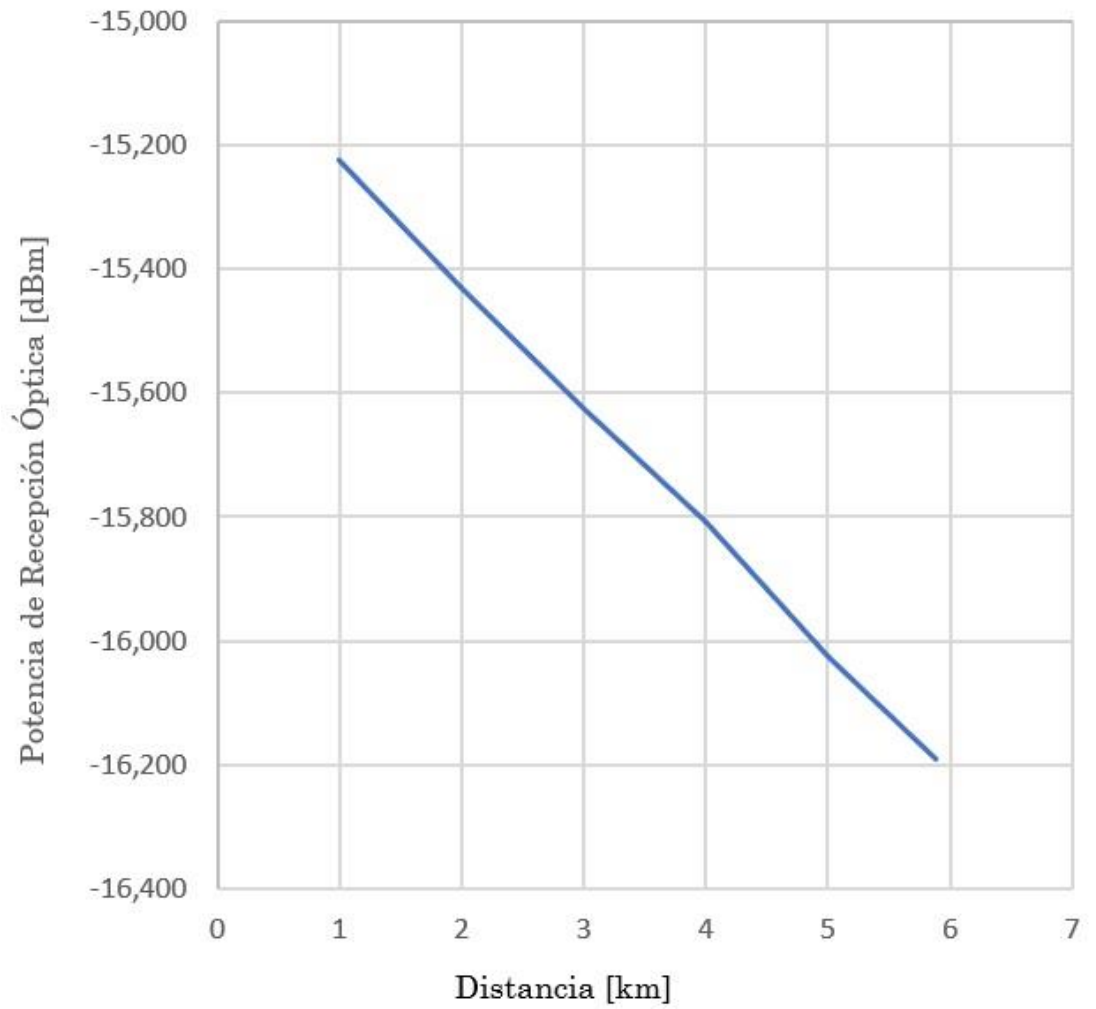

Fig. 21. Variación de la potencia de recepción óptica con la distancia para la señal radio Fuente: elaboración propia. 
Evaluación del desempeño físico de un sistema FTTH-GPON para servicios Quad Play después de la incorporación de un módulo RoF

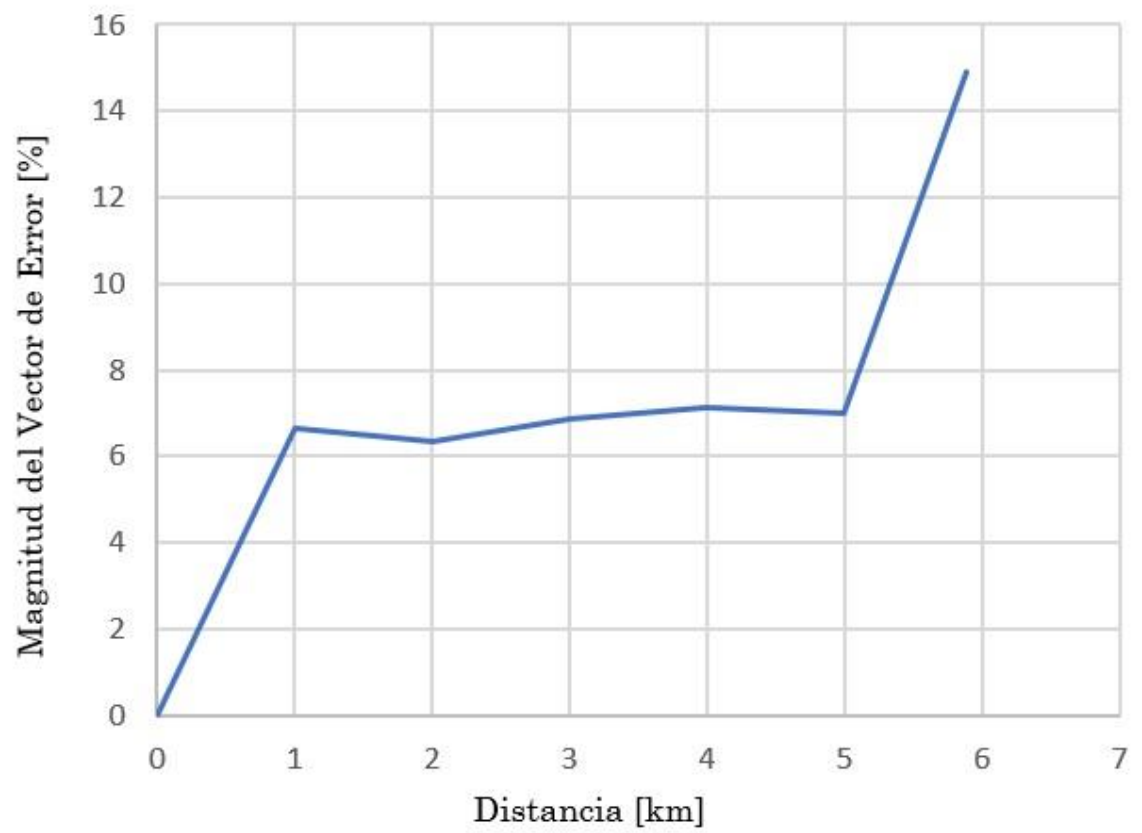

Fig. 22. Variación de la EVM con la distancia para la señal radio medida en el receptor Fuente: elaboración propia.

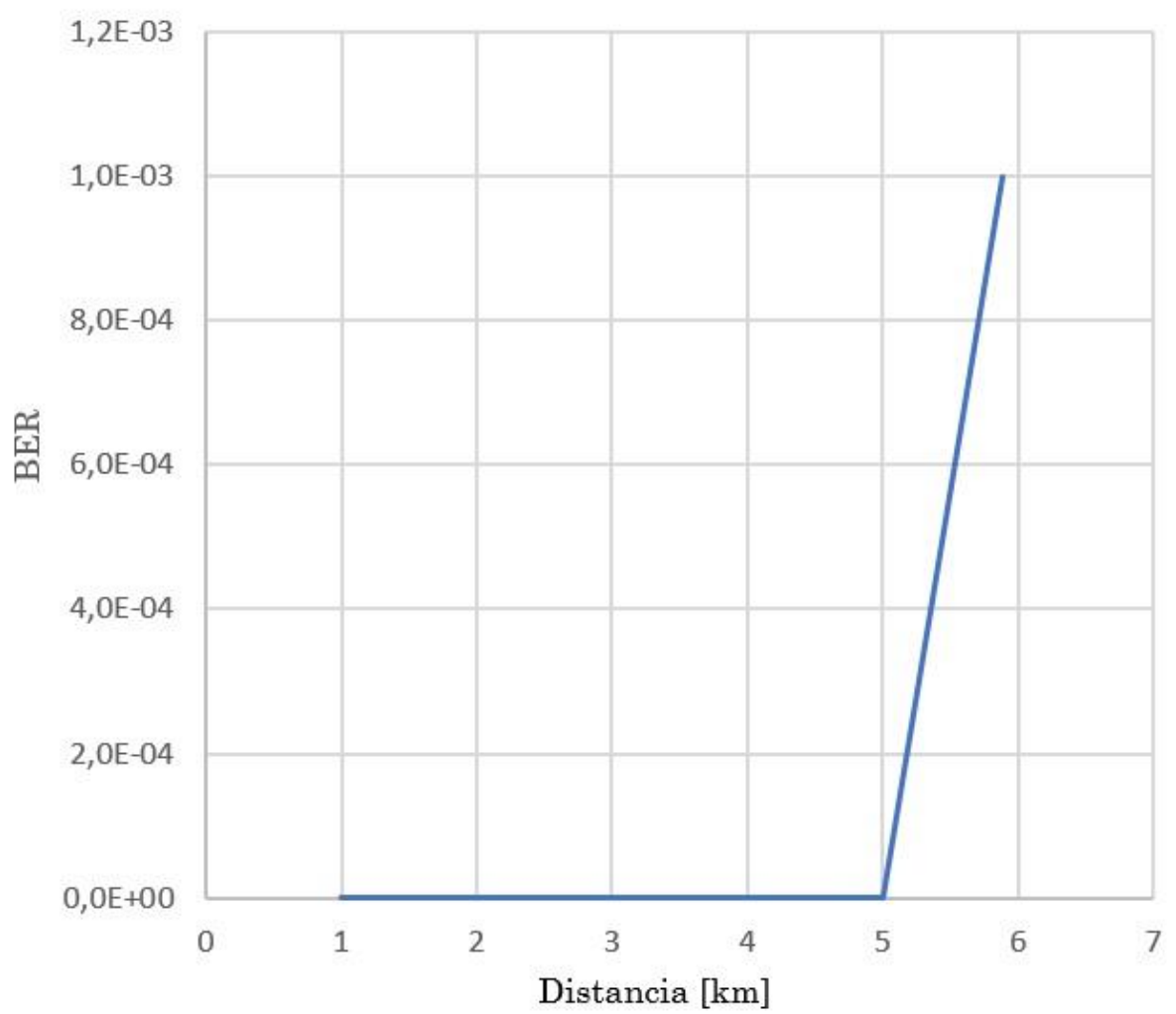

Fig. 23. Variación de la BER con la distancia para la señal radio medida en el receptor Fuente: elaboración propia. 
De la Tabla 3 se deduce que al integrar el módulo RoF a la red FTTH-GPON Triple Play, no se degrada el desempeño de los servicios de datos/voz y video. Además, se observa que se obtiene una distancia adicional de $17 \mathrm{~m}$ al integrar el módulo RoF, respecto a las pruebas aisladas. Lo anterior puede ser posible al presentarse interferencia constructiva.

\subsection{Resultados de las pruebas realizadas variando el número de ONT en la red FTH- GPON Quad Play con distancia constante y variable}

Para el caso de una sola ONT ya se definió la distancia máxima alcanzada $(5,887 \mathrm{~km})$ para el peor caso de operación que se demostró que está limitado por el módulo RoF (BER de $10^{-3}$ equivalente a un factor $Q$ de $9,8 \mathrm{~dB}$ ) la cual se usa como referencia para realizar de una forma análoga un monitoreo completo de los cuatro servicios tanto en el dominio del tiempo como en el de la frecuencia, con el fin de adquirir los resultados de los escenarios de simulación correspondientes al caso de varias ONT. Para una red FTTH-GPON en el contexto actual es suficiente operar con 64 ONT en DWDM, aunque se podría aumentar a 128 ONT con servicios Quad Play dependiendo de la cantidad de información que se requiera transportar, para lo cual se podría aumentar el número de canales (disminuyendo el espaciamiento entre ellos) y/o la velocidad de transmisión de datos (incrementando la capacidad de información).

Tabla 3. Comparación del desempeño de los servicios de la red FTTH-GPON Triple Play versus Quad Play para una sola ONT de referencia. Fuente: elaboración propia.

\begin{tabular}{|c|c|c|c|}
\hline Servicio & Parámetros & $\begin{array}{c}\text { Valor FTTH-GPON } \\
\text { Triple Play (sin el } \\
\text { módulo RoF) }\end{array}$ & $\begin{array}{c}\text { Valor FTTH-GPON } \\
\text { Quad Play (con el } \\
\text { módulo RoF) }\end{array}$ \\
\hline \multirow{3}{*}{ Datos/voz } & BER & $10^{-40}$ & $10^{-40}$ \\
\hline & Factor Q & $34,160974 \mathrm{~dB}$ & $34,291544 \mathrm{~dB}$ \\
\hline & $\begin{array}{l}\text { Potencia } \mathrm{Rx} \\
\text { óptica }\end{array}$ & $-16,1 \mathrm{dBm}$ & $-15,5 \mathrm{dBm}$ \\
\hline \multirow{3}{*}{ Video } & BER & $4,19633 \times 10^{-7}$ & $3,69857 \times 10^{-7}$ \\
\hline & Factor Q & $13,783102 \mathrm{~dB}$ & $13,924103 \mathrm{~dB}$ \\
\hline & $\begin{array}{l}\text { Potencia } \mathrm{Rx} \\
\text { óptica }\end{array}$ & $-16,1 \mathrm{dBm}$ & $-15,5 \mathrm{dBm}$ \\
\hline \multirow{3}{*}{ Radio } & EVM & $14,81868 \%$ * & $14,87726 \%$ \\
\hline & BER & $0,9545 \times 10^{-3} *$ & $0,9926 \times 10^{-3}$ \\
\hline & $\begin{array}{l}\text { Potencia Rx } \\
\text { óptica }\end{array}$ & $-15,5 \mathrm{dBm}$ * & $-16,192 \mathrm{dBm}$ \\
\hline $\begin{array}{c}\text { Fibra } \\
\text { SMF-28 }\end{array}$ & Distancia & $1,250 \mathrm{~km}$ * & $1,267 \mathrm{~km}$ \\
\hline $\begin{array}{c}\text { Fibra } \\
\text { CorningLEAF }\end{array}$ & Distancia & $5,860 \mathrm{~km} *$ & $5,877 \mathrm{~km}$ \\
\hline
\end{tabular}

*Estos datos corresponden al módulo RoF independiente, antes de ser integrado a la red FTTH-GPON Triple Play 
Evaluación del desempeño físico de un sistema FTTH-GPON para servicios Quad Play después de la incorporación de un módulo RoF

Tabla 4. Distribución de canales (DWDM) para los servicios Quad Play en la red FTTH-GPON Fuente: elaboración propia.

\begin{tabular}{|c|c|c|c|c|c|c|c|}
\hline ONT & f [THz] & $\lambda[\mathrm{nm}]$ & Etiqueta & ONT & f [THz] & $\lambda[\mathrm{nm}]$ & Etiqueta \\
\hline ONTs_video & 193,4 & 1550 & freq1_THz & 33 & 196,8 & 1523,3 & Tx33 \\
\hline 1 & 193,6 & 1548,5 & $\mathrm{Tx} 1$ & 34 & 196,9 & 1522,6 & $\mathrm{Tx} 34$ \\
\hline 2 & 193,7 & 1547,7 & $\mathrm{Tx} 2$ & 35 & 197 & 1521,8 & $\mathrm{Tx} 35$ \\
\hline 3 & 193,8 & 1546,9 & $\mathrm{Tx} 3$ & 36 & 197,1 & 1521 & Tx36 \\
\hline 4 & 193,9 & 1546,1 & $\mathrm{Tx} 4$ & 37 & 197,2 & 1520,2 & Tx37 \\
\hline 5 & 194 & 1545,3 & Tx5 & 38 & 197,3 & 1519,5 & $\mathrm{Tx} 38$ \\
\hline 6 & 194,1 & 1544,5 & Tx6 & 39 & 197,4 & 1518,7 & Tx39 \\
\hline 7 & 194,2 & 1543,7 & $\mathrm{Tx} 7$ & 40 & 197,5 & 1517,9 & $\mathrm{Tx} 40$ \\
\hline 8 & 194,3 & 1542,9 & $\mathrm{Tx} 8$ & 41 & 197,6 & 1517,2 & $\mathrm{Tx} 41$ \\
\hline 9 & 194,4 & 1542,1 & $\mathrm{Tx} 9$ & 42 & 197,7 & 1516,4 & $\mathrm{Tx} 42$ \\
\hline 10 & 194,5 & 1541,3 & $\mathrm{Tx} 10$ & 43 & 197,8 & 1515,6 & $\mathrm{Tx} 43$ \\
\hline 11 & 194,6 & 1540,6 & $\mathrm{Tx} 11$ & 44 & 197,9 & 1514,9 & $\mathrm{Tx} 44$ \\
\hline 12 & 194,7 & 1539,8 & $\mathrm{Tx} 12$ & 45 & 198 & 1514,1 & $\mathrm{Tx} 45$ \\
\hline 13 & 194,8 & 1539 & $\mathrm{Tx} 13$ & 46 & 198,1 & 1513,3 & $\mathrm{Tx} 46$ \\
\hline 14 & 194,9 & 1538,2 & $\mathrm{Tx} 14$ & 47 & 198,2 & 1512,6 & $\mathrm{Tx} 47$ \\
\hline 15 & 195 & 1537,4 & $\mathrm{Tx} 15$ & 48 & 198,3 & 1511,8 & $\mathrm{Tx} 48$ \\
\hline 16 & 195,1 & 1536,6 & $\mathrm{Tx} 16$ & 49 & 198,4 & 1511,1 & $\mathrm{Tx} 49$ \\
\hline 17 & 195,2 & 1535,8 & $\mathrm{Tx} 17$ & 50 & 198,5 & 1510,3 & $\mathrm{Tx} 50$ \\
\hline 18 & 195,3 & 1535 & $\mathrm{Tx} 18$ & 51 & 198,6 & 1509,5 & $\mathrm{Tx} 51$ \\
\hline 19 & 195,4 & 1534,3 & $\mathrm{Tx} 19$ & 52 & 198,7 & 1508,8 & $\mathrm{Tx} 52$ \\
\hline 20 & 195,5 & 1533,5 & $\mathrm{Tx} 20$ & 53 & 198,8 & 1508 & Tx53 \\
\hline 21 & 195,6 & 1532,7 & $\mathrm{Tx} 21$ & 54 & 198,9 & 1507,3 & $\mathrm{Tx} 54$ \\
\hline 22 & 195,7 & 1531,9 & $\mathrm{Tx} 22$ & 55 & 199 & 1506,5 & $\mathrm{Tx} 55$ \\
\hline 23 & 195,8 & 1531,1 & $\mathrm{~T} \times 23$ & 56 & 199,1 & 1505,7 & Tx56 \\
\hline 24 & 195,9 & 1530,3 & $\mathrm{Tx} 24$ & 57 & 199,2 & 1505 & $\mathrm{Tx} 57$ \\
\hline 25 & 196 & 1529,6 & $\mathrm{Tx} 25$ & 58 & 199,3 & 1504,2 & Tx58 \\
\hline 26 & 196,1 & 1528,8 & $\mathrm{Tx} 26$ & 59 & 199,4 & 1503,5 & Tx59 \\
\hline 27 & 196,2 & 1528 & $\mathrm{Tx} 27$ & 60 & 199,5 & 1502,7 & Tx60 \\
\hline 28 & 196,3 & 1527,2 & $\mathrm{Tx} 28$ & 61 & 199,6 & 1502 & Tx61 \\
\hline 29 & 196,4 & 1526,4 & $\mathrm{~T} \times 29$ & 62 & 199,7 & 1501,2 & $\mathrm{Tx} 62$ \\
\hline 30 & 196,5 & 1525,7 & $\mathrm{Tx} 30$ & 63 & 199,8 & 1500,5 & $\mathrm{Tx} 63$ \\
\hline 31 & 196,6 & 1524,9 & Tx31 & 64 & 199,9 & 1499,7 & Tx64 \\
\hline 32 & 196,7 & 1524,1 & $\mathrm{Tx} 32$ & ONTs datos/voz & 201,2 & 1490 & freq2_THz \\
\hline
\end{tabular}

Además, cabe notar que los parámetros de simulación (frecuencia, longitud de onda, número de ONT, constante de atenuación y constante de dispersión) usados en los escenarios de una sola ONT para la fibra, se mantienen constantes para que puedan usarse dentro de estos escenarios variando el número de ONT y la distancia, los cuales constan de varias portadoras de radio inyectadas a la fibra simultáneamente, además de las dos portadoras que siempre están presentes (portadora de Internet/VoIP y portadora de CATV digital), las cuales van tomando 
valores dentro del espectro óptico para la ventana de $1550 \mathrm{~nm}$ en DWDM de acuerdo a un plan de frecuencias, a fin de proceder a observar y analizar los parámetros de medida de acuerdo a los resultados obtenidos (PRxo, EVM, SNR, BER, y distancia máxima alcanzada). Es importante aclarar que el número y valor de longitudes de onda están asignadas por el plan de frecuencias que se muestra en la Tabla 4.

La Tabla 4 muestra la distribución de los canales cuando se escala el número de los mismos, es decir, cuando se inyectan a la fibra simultáneamente: 2 canales (ONT1-ONT2), 4 canales (ONT1-ONT4), 8 canales (ONT1- ONT8), 16 canales (ONT1- ONT16), 32 canales (ONT1ONT32) y 64 canales (ONT1- ONT64).

Posteriormente se aumentó el número de ONT empleando 2, 4, 8, 16, 32 y 64 canales de acuerdo al plan de frecuencias DWDM establecido para las portadoras del servicio de Internet móvil. Se dejó la distancia máxima fija de $5,887 \mathrm{~km}$, luego, se varío la distancia desde $0 \mathrm{~km}$ hasta $5,887 \mathrm{~km}$ en pasos de $1 \mathrm{~km}$.

Se realizaron pruebas de simulación forzando el sistema al peor caso de desempeño mínimo aceptable (limitado por el módulo de radio con una BER de $10^{-3}$ ) para extraer el valor de la máxima distancia entre la OLT y las ONT.

Los resultados obtenidos muestran que el desempeño del sistema conjunto se degradó en términos de la distancia máxima alcanzada. En concordancia con la teoría, se considera que dicha degradación fue resultado de las causas principales de la distorsión en la forma de la onda óptica tales como: variaciones de la potencia del canal óptico debido a variaciones de ganancia, desviación de la frecuencia o longitud de onda del valor nominal (efecto chirp [28]), dispersión de la fibra, pérdidas de la fibra (atenuación) e interferencia destructiva, principalmente por diafonía y por la mezcla de cuatro ondas (FWM), que de acuerdo con la Recomendación ITU-T
G.697 son degradaciones ópticas de ocurrencia relativa elevada-media, respectivamente. Por lo tanto, fue necesario ajustar la distancia (reduciéndola) con el fin de garantizar los cuatro servicios en todas las ONT presentes.

Anteriormente, en la Fig. 12 se había mostrado la red FTTH-GPON con el módulo RoF integrado para el caso de una sola ONT, y ahora la Fig. 24 lo hace para 64 ONT. Es importante aclarar que la Fig. 24 muestra el modelo correspondiente a los escenarios de simulación usando varias ONT, donde es pertinente mencionar que los transmisores (OLT) y receptores (ONT) están plasmados como agrupación en modo componente (caja negra) tomando como referencia el modelo detallado que se usó para una sola ONT (Fig. 12).

A continuación, se muestran los resultados totales correspondientes a las pruebas realizadas para el caso de varias ONT. Se empieza con la referencia que sería una ONT y se continua con 2 canales, indicando los resultados del monitoreo respectivo sin variar la distancia (es decir, dejando constante la distancia máxima alcanzada de referencia limitada por el diseño del módulo RoF propuesto que corresponde a $5,887 \mathrm{~km}$ ) y dejando todo lo demás constante, pasando de manera similar al mismo proceso con 4, 8, 16, $32 \mathrm{y}$ 64 canales, como se observa en las Tablas 5 y 6 donde, del total de resultados, se han escogido como muestra el de una sola ONT y el de ocho ONT. Con la distancia máxima fija de $5,887 \mathrm{~km}$, dichas tablas sirven de referencia para tenerlas en cuenta cuando se varíe la distancia más adelante.

La Tabla 5 es un resumen de lo que ya se había analizado anteriormente para el caso de una sola ONT; es decir, corresponde a la evaluación del desempeño a nivel físico de un sistema FTTH-GPON para servicios Quad Play al integrar un módulo RoF actuando solamente una portadora de radio. 
Evaluación del desempeño físico de un sistema FTTH-GPON para servicios Quad Play después de la incorporación de un módulo RoF

Oficina Central (OLT)

Casa (ONT)

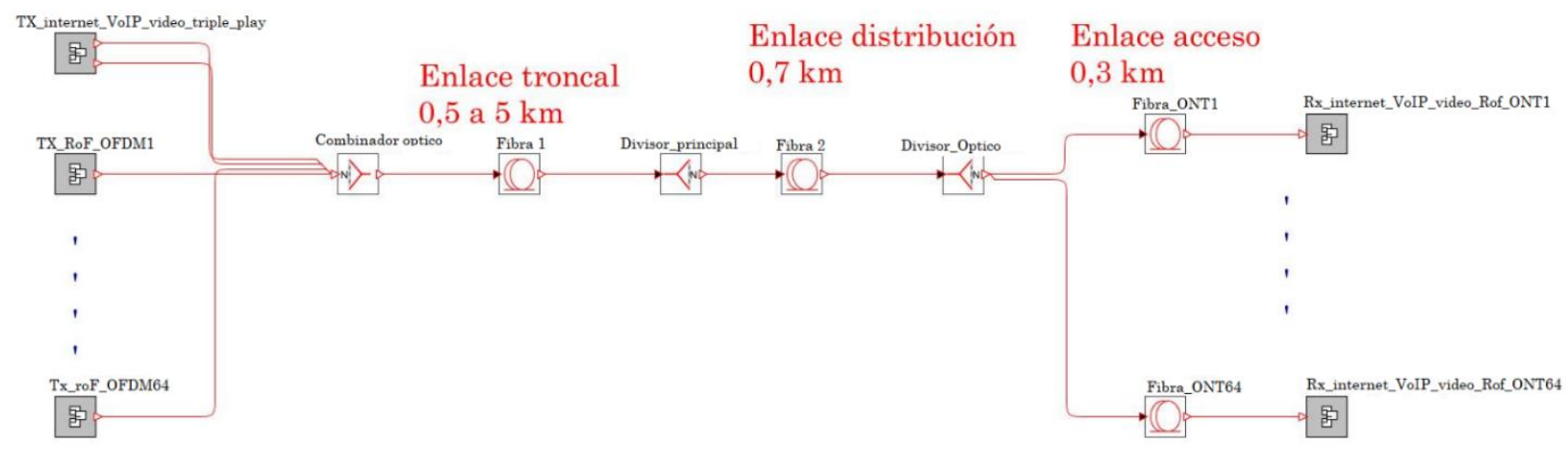

Fig. 24. Modelo general del sistema FTTH-GPON Quad Play para 64 ONT

Fuente: elaboración propia.

Tabla 5. Resultados de OPM en la red FTTH-GPON Quad Play para una ONT (Distancia constante) Fuente: elaboración propia.

\begin{tabular}{crrrccrr}
\hline ONT & D [km] & EVM [\%] & SNR [dB] & SNR [lineal] & BER (con SNR [lineal]) & BER (aprox) \\
\hline 1 & 5,887 & 14,88726 & 16,543705 & 45,120142 & 0,000999201 & 0,9992 & E-03 \\
\hline
\end{tabular}

Ahora se procede a realizar la evaluación del desempeño a nivel físico de un sistema FTTH-GPON para servicios Quad Play al integrar un módulo RoF cuando ya están actuando simultáneamente $2,4,8,16,32$ y 64 ONT.

Cabe aclarar que para cada ONT le corresponde un módulo RoF, por lo que cada señal de radio se monta sobre una portadora óptica. En concordancia con el plan de frecuencias de la Tabla 4, cuando las primeras 8 portadoras de radio (ONT1ONT8) están presentes junto con las portadoras de datos/voz y video, el desempeño de sistema conjunto empeoró posiblemente debido a la interferencia destructiva (efecto negativo de la diafonía y de FWM). Es decir, para el peor de los casos ocurridos en la ONT6, la EVM se incrementó del $14,877 \%$ al $21,949 \%$, lo cual implica que la BER empeoró pues pasó de $1 \times 10^{-3}$ a $15,6 \times 10^{-3}$, según se muestra en la Tabla 6. Lo anterior, entorpece el desempeño general del sistema, para lo cual se debe ajustar la distancia (reduciéndola) con el fin de garantizar los cuatro servicios en todas las ONT presentes.

Otra forma de evaluar el desempeño del sistema cuando se emplean desde 8 canales hasta 64 canales, es precisar que si se aumenta la distancia por encima de la máxima alcanzada en cada caso particular (8 ONT, 16 ONT, 32 ONT y 64 ONT), el desempeño del sistema empeorará $\left(\mathrm{EVM}>14,877\right.$ \% y $\left.\mathrm{BER}>10^{-3}\right)$ y no se podrá garantizar calidad de servicio (QoS).

Para este contexto multicanal, es importante resaltar la importancia por el impacto que tiene la diafonía (cross-talk) óptica en el desempeño del sistema. La diafonía se presenta de forma diferente debido a que las señales son transmitidas por medio de luz, por tanto, en sistemas WDM dicho fenómeno se manifiesta como la perturbación que puede ocasionar interferencia entre una longitud de onda frente a otra, dependiendo de la separación que exista entre ellas (interferencia de los canales). En el suplemento 39 A de las Recomendaciones ITU-T de la serie G se usan unas expresiones particulares con el fin de puntualizar los efectos de la diafonía óptica.

Se llama diafonía entre canales a la perturbación que ejercen los canales adyacentes sobre el canal deseado; en otras palabras, es la relación de la potencia total en los canales perturbadores a la del canal deseado, aclarando que las longitudes de 
onda de los canales deseado y adyacentes son diferentes. Paralelamente es posible que se produzca diafonía (interferencia entre canales) debido a la posible variación de las frecuencias centrales y a la demultiplexación anómala.

La diafonía entre canales se produce especialmente debido a la demultiplexación anómala de una señal de transmisión multicanal en sus canales individuales, previamente a la transferencia hacia un conjunto de receptores monocanal.

El proceso más nocivo para un canal es cuando su potencia de transmisión se encuentra en el valor mínimo y el resto de los canales contiguos se encuentran en su máximo. Además, es importante resaltar que la penalidad de diafonía también depende de las velocidades binarias relativas de las señales deseada e interferente y de los códigos de línea [29], teniendo en cuenta que en el presente trabajo el servicio de datos/voz y radio operan con $0 \mathrm{dBm}$ pero el de video con 8 $\mathrm{dBm}$, y sus velocidades binarias relativas son distintas, para voz/datos 1,5 Gbps, video 0,8 Gbps y radio $10 \mathrm{Gbps}$.

Adicionalmente, en concordancia con la teoría de los efectos no lineales de la fibra óptica [16], la mezcla de cuatro ondas (FWM) se debe al índice refractivo dependiente de la intensidad. Este efecto se ve descrito por una interacción paramétrica entre ondas ópticas de manera muy parecida a la distorsión de intermodulación que se produce en los sistemas eléctricos. El efecto FWM de igual manera es producido únicamente en sistemas multicanal, en los cuales, los choques entre dos o más canales causan la generación de una o más frecuencias a expensas de la pérdida de potencia de los canales originales.

Para explicar claramente el funcionamiento de esta no linealidad se supone que se tiene tres ondas ópticas a frecuencias $f_{i}, f_{j} y f_{k}$ que ingresan al núcleo de una fibra óptica, esto, generará nuevos componentes de frecuencia definidos como
$f_{F W M}=f i+f j-f k$. El número de bandas laterales debido a la FWM se incrementa geométricamente de acuerdo a (4):

$$
M=\frac{1}{2}\left(N_{c h}^{3}-N_{c h}^{2}\right)
$$

Donde, $\mathrm{M}$ es el número de las bandas laterales creadas, y $\mathrm{N}_{\mathrm{ch}}$ es el número de canales.

De (4) se puede verificar que, como para el caso del presente trabajo, si se tienen 66 canales (64 de radio, uno de datos/voz y otro de video), esto generaría 141.570 bandas laterales adicionales, que podrían afectar directamente en los canales con señal óptica útil, es por eso que se hace necesaria una supresión de la mezcla de cuatro señales FWM, para evitar interferencias importantes entre los canales de señal y los componentes de frecuencia FWM [30].

Análogamente a los resultados mostrados cuando la distancia es constante, se procede a mostrar los resultados totales correspondientes a las pruebas realizadas para el caso de varias ONT. Se empieza con la referencia que sería una ONT y se continua con 2 canales, indicando los resultados del monitoreo respectivo pero ahora variando la distancia (es decir, iniciando desde el caso que garantiza el acceso de "último kilómetro" hasta alcanzar la máxima distancia en cada caso particular relacionado con el número de ONT empleado) y dejando todo lo demás constante, pasando de manera similar al mismo proceso con 4, 8, 16, 32 y 64 canales, como se observa en la Tablas 7 y 8 donde se adicionaron los datos de la PRxo como otro parámetro OPM a tener en cuenta, seleccionando como muestra uno y ocho ONT. Las Tablas 5 y 6, mostradas anteriormente, sirvieron de referencia para hacer la proyección de la distancia máxima alcanzada en cada caso de acuerdo a la limitante del servicio de Internet móvil en cuanto al valor máximo de la BER permitido $\left(10^{-3}\right)$, es decir, fue necesario 
Evaluación del desempeño físico de un sistema FTTH-GPON para servicios Quad Play después de la incorporación de un módulo RoF

forzar al sistema para el peor caso de desempeño mínimo aceptable y por tal vía extraer el valor de la máxima distancia alcanzada entre la OLT y las respectivas ONT.

Por lo anterior, tras haber comentado sobre la diafonía y el efecto FWM al aumentar el número de canales, fue posible analizar la incidencia de incrementar el número de ONT comparado con la máxima distancia de referencia para una ONT, porque, con el fin de mantener el desempeño general del sistema al valor mínimo aceptable, se debe sacrificar la distancia alcanzada entre OLT y ONT, como se muestra en las Tablas 6 y 7 .

Cuando se emplea un solo canal, o inclusive dos y hasta cuatro canales, el desempeño del sistema sigue siendo comparativamente el mismo ya que no hay sacrificio de distancia (BER en $10^{-3}$ ).
La Tabla 6 es un resumen de los resultados de desempeño del sistema al variar la distancia desde $1 \mathrm{~km}$ hasta 5,887 $\mathrm{km}$, con incrementos de $1 \mathrm{~km}$ entre cada prueba para el caso de una sola ONT, es decir, corresponde a la evaluación del desempeño a nivel físico de un sistema FTTH-GPON para servicios Quad Play al integrar un módulo RoF actuando solamente una portadora de radio, y es congruente con los resultados del peor caso de referencia mostrados en la Tabla 5.

Recapitulando, se procede a realizar la evaluación del desempeño a nivel físico de un sistema FTTH-GPON para servicios Quad Play al integrar un módulo RoF cuando ya están actuando simultáneamente $2,4,8,16,32$ y 64 portadoras de radio, teniendo en cuenta que además se va a variar la distancia entre la OLT y ONT.

Tabla 6. Resultados de OPM en la red FTTH-GPON Quad Play para 8 ONT (Distancia constante)

Fuente: elaboración propia.

\begin{tabular}{lclllcll}
\hline ONT & D [km] & EVM [\%] & SNR [dB] & SNR [lineal] & BER (con SNR [lineal]) & BER (aprox) \\
\hline 1 & 5,887 & 7,926977 & 22,01785 & 159,1419971 & $6,31546 \mathrm{E}-09$ & & \\
2 & 5,887 & 7,410307 & 22,60328 & 182,107402 & $5,96032 \mathrm{E}-10$ & & \\
3 & 5,887 & 7,168321 & 22,89165 & 194,6099809 & $1,65406 \mathrm{E}-10$ & & \\
4 & 5,887 & 8,874023 & 21,03759 & 126,9868938 & $1,74957 \mathrm{E}-07$ & & \\
5 & 5,887 & 16,06435 & 15,88274 & 38,75017647 & 0,002014181 & 2,014181 & E-03 \\
6 & 5,887 & 21,94926 & 13,1716 & 20,75679203 & 0,015600426 & 15,60043 & E-03 \\
7 & 5,887 & 21,93346 & 13,17786 & 20,78670755 & 0,015545408 & 15,54541 & E-03 \\
8 & 5,887 & 14,97999 & 16,48977 & 44,56325992 & 0,001062006 & 1,062006 & E-03 \\
\hline
\end{tabular}

Tabla 7. Resultados de OPM en la red FTTH-GPON Quad Play para una ONT (Distancia variable) Fuente: elaboración propia.

\begin{tabular}{|c|c|c|c|c|c|c|c|}
\hline ONT & $\mathrm{D}[\mathrm{km}]$ & PRxo [dBm] & EVM [\%] & SNR [dB] & SNR [lin] & BER (con SNR [lin]) & BER (aprox) \\
\hline \multirow{6}{*}{1} & 1 & $-15,224$ & 6,644045 & 23,551349 & 226,53477 & $6,31687 \mathrm{E}-12$ & \\
\hline & 2 & $-15,428$ & 6,355649 & 23,936802 & 247,55984 & 7,3937E-13 & \\
\hline & 3 & $-15,627$ & 6,854632 & 23,280317 & 212,82944 & $2,56278 \mathrm{E}-11$ & \\
\hline & 4 & $-15,81$ & 7,129899 & 22,938332 & 196,71308 & $1,33348 \mathrm{E}-10$ & \\
\hline & 5 & $-16,026$ & 7,012759 & 23,082222 & 203,3397 & $6,76587 \mathrm{E}-11$ & \\
\hline & 5,887 & $-16,192$ & 14,88726 & 16,543705 & 45,120142 & 0,000999201 & 0,9992 E-03 \\
\hline
\end{tabular}


Las Tablas 6 y 7 son un resumen de los resultados de desempeño del sistema al variar la distancia desde $1 \mathrm{~km}$ hasta $5 \mathrm{~km}$, con incrementos de $1 \mathrm{~km}$ entre cada prueba para el caso de ocho ONT, es decir, corresponde a la evaluación del desempeño a nivel físico de un sistema FTTH-GPON para servicios Quad Play al integrar un módulo RoF actuando con 8 portadoras de radio, y es congruente con los resultados del peor caso de referencia mostrados en la Tabla 6. Sin embargo, para este caso se evidencia un sacrificio de distancia porque las degradaciones ópticas ya empiezan a ser apreciables. Por lo anterior, las pruebas de ajuste del sistema arrojaron que la máxima distancia con el fin de mantener un desempeño aceptable y darle servicio a todas las 8 ONT simultáneamente, bajó de $5,887 \mathrm{~km}$ a $3,830 \mathrm{~km}$ (con máxima EVM de $14,877 \%$ y máxima BER de $10^{-3}$ ), por lo que, al pasar de 4 a 8 canales, la penalidad relativa en distancia corresponde a 2,057 $\mathrm{km}$. Entonces, la penalidad acumulativa en distancia con respecto a un solo canal se mantiene en $2,057 \mathrm{~km}$.

En la Fig. 24 se muestra el modelo general del sistema FTTH-GPON Quad Play para 64 ONT. Por su parte, la Fig. 25 muestra el espectro de frecuencias en el canal óptico correspondiente a la red FTTH-GPON Quad Play para 64 ONT, con lo cual se evidencia que fue el escenario de simulación global de la Fig. 24 que se implementó en este trabajo, en concordancia con el plan de frecuencias de la Tabla 4.

Con el fin de resumir todos los resultados de las distintas pruebas hechas en los escenarios de simulación, la Tabla 9 compara el desempeño de los servicios de la red FTTH-GPON Quad Play para varias ONT especificando el alcance máximo.

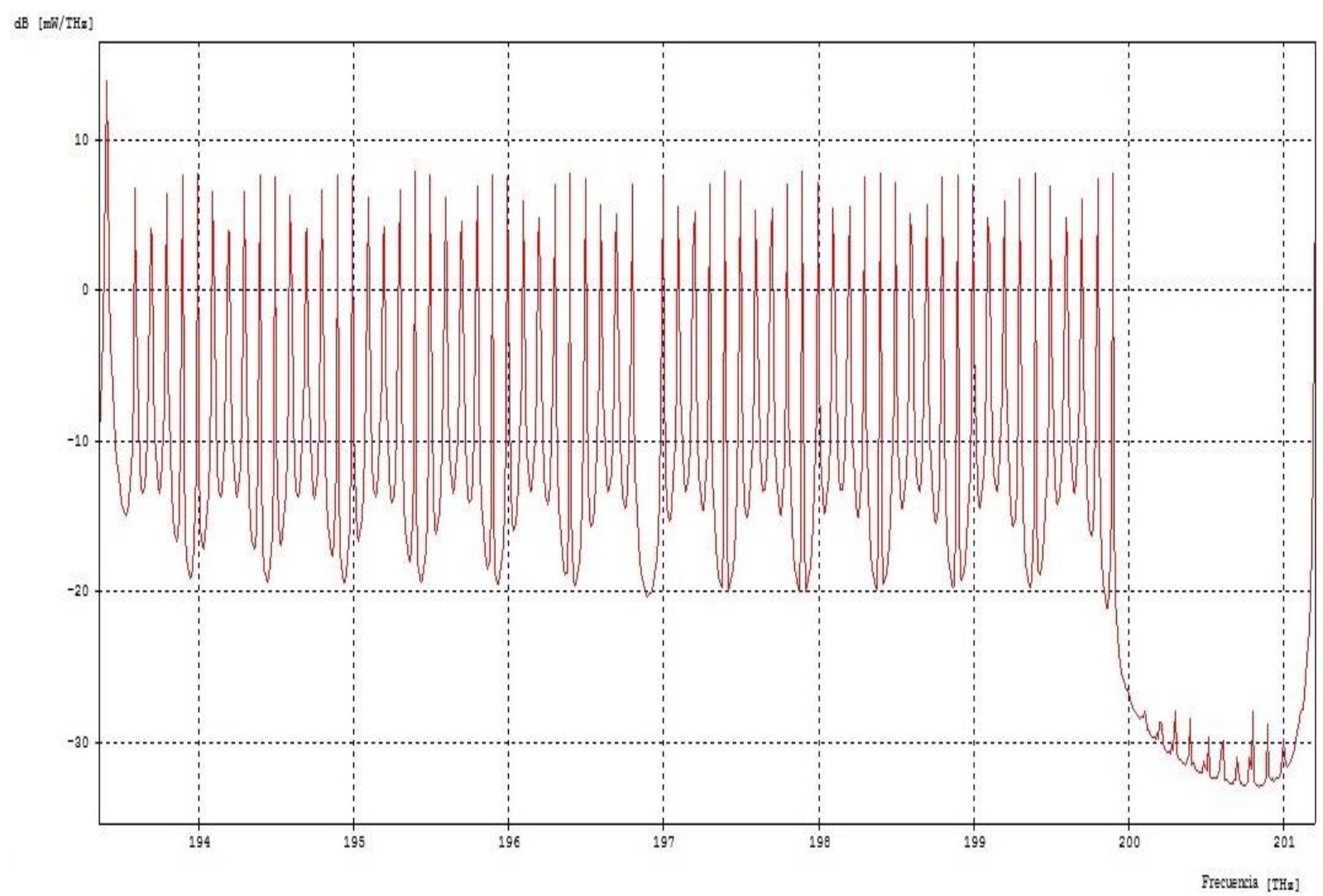

Fig. 25. Espectro de frecuencias para de la red FTTH-GPON Quad Play para 64 ONT Fuente: elaboración propia. 
Evaluación del desempeño físico de un sistema FTTH-GPON para servicios Quad Play después de la incorporación de un módulo RoF

Tabla 8. Resultados de OPM en la red FTTH-GPON Quad Play para ocho ONT (Distancia variable)

Fuente: elaboración propia.

\begin{tabular}{|c|c|c|c|c|c|c|c|c|}
\hline ONT & $\mathrm{D}[\mathrm{km}]$ & PRxo [dBm] & EVM [\%] & SNR [dB] & SNR [lin] & $\begin{array}{c}\text { BER } \\
(\text { con SNR [lin]) }\end{array}$ & \multicolumn{2}{|c|}{ BER (aprox) } \\
\hline \multirow{5}{*}{1} & 1 & $-15,211$ & 7,320126 & 22,70962887 & 186,6220204 & $3,75094 \mathrm{E}-10$ & & \\
\hline & 2 & $-15,41$ & 7,277239 & 22,76066723 & 188,8281435 & $2,99156 \mathrm{E}-10$ & & \\
\hline & 3 & $-15,628$ & 6,943219 & 23,16878272 & 207,4332025 & $4,45047 \mathrm{E}-11$ & & \\
\hline & 4 & $-15,815$ & 7,659611 & 22,31586572 & 170,445905 & 1,97412E-09 & & \\
\hline & 5 & $-16,008$ & 8,020366 & 21,91611625 & 155,4574807 & 9,23053E-09 & & \\
\hline \multirow{5}{*}{2} & 1 & $-15,22$ & 7,024872 & 23,06723169 & 202,6390633 & 7,26889E-11 & & \\
\hline & 2 & $-15,421$ & 6,582257 & 23,6325033 & 230,8077195 & $4,08351 \mathrm{E}-12$ & & \\
\hline & 3 & $-15,596$ & 6,990821 & 23,10943636 & 204,6179059 & 5,93623E-11 & & \\
\hline & 4 & $-15,796$ & 6,676266 & 23,50932736 & 224,3534418 & $7,8932 \mathrm{E}-12$ & & \\
\hline & 5 & $-16,061$ & 7,166576 & 22,89376578 & 194,7047642 & $1,63808 \mathrm{E}-10$ & & \\
\hline \multirow{5}{*}{3} & 1 & $-15,208$ & 6,764148 & 23,39573797 & 218,5615677 & $1,42639 \mathrm{E}-11$ & & \\
\hline & 2 & $-15,418$ & 6,463336 & 23,79086533 & 239,3792671 & $1,7028 \mathrm{E}-12$ & & \\
\hline & 3 & $-15,586$ & 6,702103 & 23,47577804 & 222,6269847 & $9,41546 \mathrm{E}-12$ & & \\
\hline & 4 & $-15,806$ & 7,79269 & 22,166252 & 164,6740627 & 3,5738E-09 & & \\
\hline & 5 & $-15,993$ & 7,102088 & 22,97227902 & 198,256713 & $1,13848 \mathrm{E}-10$ & & \\
\hline \multirow{5}{*}{4} & 1 & $-15,221$ & 7,202674 & 22,85012483 & 192,7580316 & $1,99968 \mathrm{E}-10$ & & \\
\hline & 2 & $-15,405$ & 6,280508 & 24,04010454 & 253,5189653 & $4,02794 \mathrm{E}-13$ & & \\
\hline & 3 & $-15,581$ & 6,402769 & 23,87264333 & 243,9295041 & $1,07057 \mathrm{E}-12$ & & \\
\hline & 4 & $-15,83$ & 6,981241 & 23,12134739 & 205,1798646 & $5,60449 \mathrm{E}-11$ & & \\
\hline & 5 & $-16,041$ & 7,640157 & 22,33795434 & 171,315017 & $1,80543 \mathrm{E}-09$ & & \\
\hline \multirow{5}{*}{5} & 1 & $-15,219$ & 6,508271 & 23,73068743 & 236,0851896 & $2,38296 \mathrm{E}-12$ & & \\
\hline & 2 & $-15,421$ & 6,548237 & 23,67751221 & 233,212176 & $3,19482 \mathrm{E}-12$ & & \\
\hline & 3 & $-15,63$ & 7,224593 & 22,82373228 & 191,5901723 & $2,25392 \mathrm{E}-10$ & & \\
\hline & 4 & $-15,834$ & 7,051332 & 23,03457674 & 201,1211176 & 8,49087E-11 & & \\
\hline & 5 & $-15,991$ & 8,765424 & 21,14454143 & 130,152988 & $1,26018 \mathrm{E}-07$ & & \\
\hline \multirow{5}{*}{6} & 1 & $-15,21$ & 7,064626 & 23,01821649 & 200,3649025 & $9,17436 \mathrm{E}-11$ & & \\
\hline & 2 & $-15,406$ & 6,590638 & 23,62145084 & 230,2210784 & $4,33552 \mathrm{E}-12$ & & \\
\hline & 3 & $-15,679$ & 8,139046 & 21,78852994 & 150,9569088 & 1,46792E-08 & & \\
\hline & 4 & $-15,846$ & 7,789679 & 22,16960877 & 164,8013925 & 3,52729E-09 & & \\
\hline & 5 & $-15,996$ & 14,40266 & 16,83114583 & 48,20749701 & 0,000713362 & 0,71336 & E-03 \\
\hline \multirow{5}{*}{7} & 1 & $-15,224$ & 6,589814 & 23,62253687 & 230,2786563 & $4,31012 \mathrm{E}-12$ & & \\
\hline & 2 & $-15,401$ & 6,865843 & 23,26612263 & 212,1349683 & $2,75139 \mathrm{E}-11$ & & \\
\hline & 3 & $-15,654$ & 7,259083 & 22,78236476 & 189,7738969 & $2,71513 \mathrm{E}-10$ & & \\
\hline & 4 & $-15,818$ & 10,11437 & 19,90122326 & 97,75125152 & $3,67455 \mathrm{E}-06$ & & \\
\hline & 5 & $-16,036$ & 21,30097 & 13,43201239 & 22,03947467 & 0,01341486 & 13,4149 & E-03 \\
\hline \multirow{5}{*}{8} & 1 & $-15,22$ & 6,780162 & 23,37519859 & 217,53035 & $1,58492 \mathrm{E}-11$ & & \\
\hline & 2 & $-15,419$ & 7,363945 & 22,65778928 & 184,4076475 & $4,70736 \mathrm{E}-10$ & & \\
\hline & 3 & $-15,572$ & 6,927711 & 23,18820476 & 208,3629395 & $4,04668 \mathrm{E}-11$ & & \\
\hline & 4 & $-15,765$ & 18,47087 & 14,67025297 & 29,31063968 & 0,00580128 & 5,80128 & E-03 \\
\hline & 5 & $-16,026$ & 19,90462 & 14,02092218 & 25,24016666 & 0,009245215 & 9,24521 & E-03 \\
\hline
\end{tabular}


Evaluación del desempeño físico de un sistema FTTH-GPON para servicios Quad Play después de la incorporación de un módulo RoF

Tabla 9. Comparación del desempeño de los servicios de la red FTTH-GPON Quad Play para varias ONT especificando el alcance máximo. Fuente: elaboración propia.

\begin{tabular}{|c|c|c|c|}
\hline Servicio & No. ONT & BER & Distancia [km] \\
\hline Datos/voz & 2 & $1 \times 10^{-40}$ & 5,88870 \\
\hline Video & 2 & $3,69857 \times 10^{-7}$ & 5,88870 \\
\hline Radio & 2 & $3,47713 \times 10^{-10}$ & 5,88870 \\
\hline Datos/voz & 4 & $1 \times 10^{-40}$ & 5,88870 \\
\hline Video & 4 & $3,69857 \times 10^{-7}$ & 5,88870 \\
\hline Radio & 4 & $3,98063 \times 10^{-8}$ & 5,88870 \\
\hline Datos/voz & 8 & $1 \times 10^{-40}$ & 5,88870 \\
\hline Video & 8 & $3,69857 \times 10^{-7}$ & 5,88870 \\
\hline Radio & 8 & $1 \times 10^{-3}$ & 3,83000 \\
\hline Datos/voz & 16 & $1 \times 10^{-40}$ & 5,88870 \\
\hline Video & 16 & $3,69857 \times 10^{-7}$ & 5,88870 \\
\hline Radio & 16 & $1 \times 10^{-3}$ & 2,35800 \\
\hline Datos/voz & 32 & $1 \times 10^{-40}$ & 5,88870 \\
\hline Video & 32 & $3,69857 \times 10^{-7}$ & 5,88870 \\
\hline Radio & 32 & $1 \times 10^{-3}$ & 1,51850 \\
\hline Datos/voz & 64 & $1 \times 10^{-40}$ & 5,88870 \\
\hline Video & 64 & $3,69857 \times 10^{-7}$ & 5,88870 \\
\hline Radio & 64 & $1 \times 10^{-3}$ & 1,30925 \\
\hline
\end{tabular}

De la Tabla 9, se deduce que a medida que se incrementa el número de ONT (y por ende de portadoras de radio), el desempeño del cuarto servicio (Internet móvil) empeora desde el orden de BER de 10-10 hasta llegar al mínimo aceptable que es una BER de $10^{-3}$; no obstante, como se está trabajando con un alcance de $5,887 \mathrm{~km}$ (limitado por el módulo RoF propuesto) para la prestación de servicios Quad Play, el desempeño de los servicios Triple Play en la red FTTH-FPON permanece invariable, puesto que su alcance máximo es de $20 \mathrm{~km}$, en concordancia con [24], [25].

Es muy importante precisar que, de acuerdo a los resultados obtenidos en [10], a velocidades de $10 \mathrm{Gbps}$, el mejoramiento en el desempeño de la transmisión usando una fibra de dispersión negativa en relación con una fibra de dispersión positiva, es mejor que a velocidades de 2,5 Gbps en cuanto al alcance máximo.
Además, cuando se utilizan láser modulados externamente, como los MachZehnder y los de realimentación distribuida tipo electroabsorción (EA-DFB) a 10 Gbps para un solo canal, también se encuentra una mejora en el desempeño (en términos de máximo alcance sin compensación de dispersión ni uso de amplificación) del sistema, utilizando una fibra de dispersión negativa que una de dispersión positiva.

Para una BER dada, el receptor tiene una mejor sensitividad (más pequeña) usando una fibra de dispersión negativa que una positiva; y consecuentemente para una sensitividad de receptor dada, se obtiene un peor desempeño (BER más grande) usando una fibra de dispersión positiva que una negativa, teniendo en cuenta que al aumentar la velocidad de transmisión de datos, la sensitividad del receptor empeora [10]. 
Finalmente, después de haber evaluado el desempeño a nivel físico de un sistema FTTH-GPON para servicios Quad Play al integrar un módulo RoF (para mayor detalle y ampliación de la información, se sugiere consultar [30]), a continuación se procede a puntualizar las conclusiones.

\section{CONCLUSIONES}

En este estudio se analizaron y evaluaron diferentes escenarios de simulación para determinar la incidencia de agregar un cuarto servicio (Internet móvil) a una red FTTH-GPON Triple Play existente, siendo la integración del módulo RoF el aporte más significativo de esta investigación por ser un módulo simple e implementable en un entorno actual como solución de "último kilómetro" para que los usuarios puedan contar con servicios Quad Play para el caso de que algún operador móvil lo ofrezca.

La integración del módulo RoF propuesto a una red FTTH-GPON Triple Play existente, no afecta el desempeño de los parámetros OPM de los servicios de datos/voz y video.

$\mathrm{Al}$ incrementar el número de ONT en una red FTTH-GPON que soporte servicios Quad Play, los resultados arrojaron una penalización en términos de la distancia máxima alcanzada entre la ONT y la OLT.

En concordancia con los resultados a lo largo de las pruebas de simulación, al realizar el monitoreo del canal óptico cuando se varia la distancia de transmisión, se determinó el desempeño de la red a través de los resultados de la EVM y de la BER.

A su vez en los escenarios de simulación multicanal tipo WDM densa (DWDM), se puede decir que:

-Todas las conclusiones obtenidas en los escenarios monocanal (una sola ONT) son aplicables a los escenarios multicanal (varias ONT), ya que se están trabajando los parámetros OPM y el caso monocanal es una referencia para el caso multicanal.

-Los resultados del trabajo muestran que inclusive se cumple con un buen desempeño usando la fibra estándar SMF28 , alcanzando una distancia de $1,250 \mathrm{~km}$ (contexto de las redes de acceso) con una portadora óptica que transporta la señal $\mathrm{RF}$, teniendo en cuenta que los operadores ya cuentan con este tipo de fibra instalada en todo el mundo, y no sería necesario cambiar la fibra por la sugerida CorningLEAF, a pesar de lograr con ella un alcance de $5,877 \mathrm{~km}$, pues su costo es más elevado.

Es importante considerar que cuando se obtuvo las distancias de referencia para el canal simple, y tras realizar varias pruebas de ajuste, se consiguieron las distancias máximas para cada número de canales de radio simultáneos. Lo que se hizo fue un barrido desde $0 \mathrm{~km}$ hasta llegar a dichas distancias de referencia (D), espaciadas cada kilómetro. Luego, al comparar la distancia obtenida de cada canal particular $\left(D_{c h}\right)$, se obtuvo que si $\mathrm{D}<\mathrm{Dch}_{\mathrm{j}}$, entonces $\mathrm{BER}_{\mathrm{j}}<10^{-3}$ (desempeño bueno), cuando $\mathrm{D}=\mathrm{Dch}_{\mathrm{j}}, \quad$ se tiene una $\mathrm{BER}_{\mathrm{j}}=10^{-3}$ (desempeño regular), y si $\mathrm{D}>\mathrm{Dch}_{\mathrm{j}}$, luego $\mathrm{BER}_{\mathrm{j}}>10^{-3}$ (desempeño malo).

A futuro es posible seguir trabajando con el fin de mejorar el desempeño del módulo RoF propuesto que sirve ahora como una referencia cuando se vaya a integrar en una red FTTH-GPON Triple Play, analizando otras alternativas que permitan incrementar la distancia máxima entre la OLT y las ONT, como por ejemplo LR-PON y WDM-PON. Para tal fin, es necesario considerar la modificación de los valores de algunos parámetros de OFDM, o usar diferentes formatos de codificación y modulación, empleando 64-QAM, 256-QAM $\mathrm{u}$ otros tipos de modulación digital que también pueden ser utilizados para este servicio. Se podrían evaluar también enfoques alternativos que permitan operar con frecuencias y velocidades de 
Evaluación del desempeño físico de un sistema FTTH-GPON para servicios Quad Play después de la incorporación de un módulo RoF

transmisión más altas, y adicionalmente tener en cuenta el enlace ascendente.

\section{AGRADECIMIENTOS}

Los autores desean expresar su reconocimiento y agradecimiento al Grupo I+D Nuevas Tecnologías en Telecomunicaciones (GNTT), perteneciente al Departamento de Telecomunicaciones de la Facultad de Ingeniería en Electrónica y Telecomunicaciones de la Universidad del Cauca, por apoyar el desarrollo de esta investigación a nivel de maestría. Además, la colaboración brindada por los ingenieros encargados del soporte de la herramienta de simulación OptSim de Synopsys, Inc. fue muy importante, destacándose la colaboración de Jigesh Patel y Aldo Peruggia. Además, se expresan agradecimientos especiales a $\mathrm{PhD}$. Chaddi Assi, experto en comunicaciones por radio y fibra óptica de la Universidad de Concordia (Canada).

\section{REFERENCIAS}

[1] CICOMRA - Cámara de Informática y Comunicaciones de la República Argentina, (2008) "Las posibilidades de las nuevas tecnologías audiovisuales en Argentina: Triple Play (Internet + Telefonía Fija + Televisión) y Cuádruple Play (Internet + Telefonía Fija + Televisión+Telefonía Móvil)," Disponible en: URL

[2] F. J. Hens y J. M. Caballero, "Quadruple Play," en Triple Play: Building the converged network for IP, VoIP and IPTV, 1a ed., Chichester: John Wiley \& Sons, Ltd, 2008, pp. 243-303.

https://doi.org/10.1002/9780470754382

[3] J. J. Granada Torres, C. M. Serpa Imbett, G. M. Varón Durán, y N. Guerrero Gonzáles, "Hacia la próxima generación de sistemas de Radio sobre Fibra de banda ancha: retos tecnológicos en la banda de las ondas milimétricas," Ing. y Desarro., vol. 29, no. 2, pp. 242-265, Jul. 2011. Disponible en: URL

[4] R. O. Muñoz Ortiz, M. A. Cely Mancipe, G. A Puerto-Leguizamón, y C. A. Suárez Fajardo, "Generación de señales para sistemas radio sobre fibra basados en combinación óptica," Ing. Investig. y Tecnol., vol. 16, no. 4, pp. 585598, Oct. 2015. https://doi.org/10.1016/j.riit.2015.09.010

[5] G. A. Puerto Leguizamón y C. A. SuárezFajardo, "Modelo analítico de generación de señales para sistemas radio sobre fibra," Dyna, vol. 81, no. 188, pp. 26-33, Dec. 2014. https://doi.org/10.15446/dyna.v81n188.39715

[6] M. Noweir et al., "Digitally Linearized RadioOver Fiber Transmitter Architecture for Cloud Radio Access Network's Downlink," IEEE Trans. Microw. Theory Tech., vol. 66, no. 7, pp. 3564-3574, Jul. 2018. https://doi.org/10.1109/TMTT.2018.2819665

[7] A. Patiño-Carrillo, G. Puerto-Leguizamón, y C. Suárez-Fajardo, "Bidirectional single sideband transmission of Millimeter Waves over Fiber for 5G Mobile Networks," TecnoLógicas, vol. 21, no. 43, pp. 15-26, Sep. 2018.

https://doi.org/10.22430/22565337.1053

[8] RSoft System Design Suite - OptSim Photonic System Design and Simulation. (2019), Synopsys Optical Solution Group. Disponible en: URL

[9] C. C. K. Chan, Optical performance monitoring: advanced techniques for nextgeneration photonic networks, California: Academic Press, 2010.

[10] A. Escallón P., J. Barrios L., y A. Toledo T., "Incidencia de los parámetros que afectan la calidad de la señal óptica en el desempeño de una red metropolitana WDM," Rev. Colomb. Tecnol. Av., vol. 2, no. 12, pp. 12-19, Jul. 2008. Disponible en: URL

[11] J. Armstrong, "OFDM for Optical Communications," J. Light. Technol., vol. 27, no. 3, pp. 189-204, Feb. 2009.

https://doi.org/10.1109/JLT.2008.2010061

[12] P. Muñoz y J. Gallardo, "Comparación de sistemas CP-OFDM y ZP-OFDM," Escuela Técnica Superior de Ingenieros de la Universidad de Sevilla, España, 2006. Disponible en: URL

[13] W. Fernández R. y A. Rodríguez R., "OFDM óptimo para la comunicación bidireccional en las redes eléctricas inteligentes," Ingeniare. Rev. Chil. Ing., vol. 26, no. 1, pp. 43-53, Mar. 2018. https://doi.org/10.4067/S071833052018000100043

[14] R. J. Millán Tejedor, "GPON (Gigabit Passive Optical Network)," Bit, ISSN 0210-3923, no. 166, pp. 63-67, Dic. 2008. Disponible en: URL

[15] M. Lattanzi y A. Graf, "Redes FTTx: Conceptos y Aplicaciones" IEEE Argentina, 2016. Disponible en: URL

[16] N. E. Amagua Masabanda y N. A. Mogro Marmol, "Análisis y simulación de un enlace de radio sobre fibra óptica (RoF) a $60 \mathrm{GHz}$," 
Evaluación del desempeño físico de un sistema FTTH-GPON para servicios Quad Play después de la incorporación de un módulo RoF

(Trabajo de grado), Universidad Politécnica Salesiana, Quito, Ecuador, 2013. Disponible en: URL

[17] G. E. Campos Hernández y G. P. Sabogal Alfaro, "Software de simulación de diferentes tipos de modulación de señales de radiofrecuencia sobre fibra óptica," Umbral Científico, no 9, pp. 76-84, Sep. 2006. Disponible en: URL

[18] A. Arvizu, J. A. Reynoso-Hernández, M. A. Chávez, y J. de D. Sánchez, "Foto-transceptor para sistemas RoF y RoFSO usando un mezclador opto-electrónico basado en PHEMT," Rev. Mex. física, vol. 58, no. 4, pp. 339-347, 2012. URL

[19] D. Guamialama Narváez, “Análisis de sistemas de generación y transporte de señales de mmW en sistemas RoF a $60 \mathrm{GHz}$," (Tesis de Maestría), Escuela Técnica Superior de Ingenieros de Telecomunicación Universidad Politécnica de Valencia, España, 2013. URL

[20] A. J. Cooper, "Fibre/radio' for the provision of cordless/mobile telephony services in the access network," Electron. Lett., vol. 26, no. 24, p. 2054, Nov. 1990. https://doi.org/10.1049/el:19901325

[21] Z. Jia, J. Yu, D. Qian, G. Ellinas, y G.-K. Chang, "Experimental Demonstration for Delivering 1-Gb/s OFDM Signals over 80-km $\mathrm{SSMF}$ in $40-\mathrm{GHz}$ Radio-over-Fiber Access Systems," en OFC/NFOEC 2008 - 2008 Conference on Optical Fiber Communication/National Fiber Optic Engineers Conference, San Diego, 2008. pp.13. https://doi.org/10.1109/OFC.2008.4528145

[22] A. Ng'oma et al., "Simple Multi-Gbps $60 \mathrm{GHz}$ Radio-over-Fiber Links Employing Optical and Electrical Data Up-Conversion and FeedForward Equalization," en Optical Fiber Communication Conference and National Fiber Optic Engineers Conference, San Diego 2009. https://doi.org/10.1364/OFC.2009.OWF2

[23] J. G. López, "Diseño de métodos Cross Layer cognitivos para redes de Comunicación Óptica de Ráfagas (OBS)," (Tesis Doctoral), Universidad del Cauca, Popayán, Colombia, 2014. Disponible en: URL
[24] J. D. Delgado Lasso y J. C. Marcillo Bravo, "Impacto de la Topología de Red FTTHGEPON en el Desempeño de Servicios Triple Play," (Trabajo de grado), Universidad del Cauca, Popayán, Colombia, 2016. Disponible en: URL

[25] M. A. Melo López, A. Toledo Tovar, G. A. Gómez Agredo, y I. F. Velasco Andrade, "Estudio de factibilidad técnico - económico para la implementación de una red FTTH/GPON en el contexto colombiano para servicios Triple Play,"Perspectiv@s, vol. 15, no. 16, pp. 50-63, Apr. 2018. Disponible en: URL

[26] N. J. Gomes et al., "Radio-over-fiber transport for the support of wireless broadband services [Invited]," J. Opt. Netw., vol. 8, no. 2, pp. 156178, $\quad$ Feb. 2009. https://doi.org/10.1364/JON.8.000156

[27] R. M. Roldán Giraldo, "Quadrature Amplitude Modulated (QAM) Microwave Signal Transmission over Radio-over-Fibre Link using Semiconductor Optical Amplifier," (Tesis de Maestría), University of Limerick, Limerick, Irland, 2008. Disponible en: URL

[28] M. Zamorano, E. Moschim, y S. Rossi, "Análisis del Efecto del Chirp Sobre el Desempeño de un Sistema Óptico," Rev. Fac. Ing., no. 7, pp. 29-34, Jan, 2000. URL

[29] A. F. Escallón Portilla y J. R. Barrios Lis, "Criterios para el monitoreo del canal óptico y la incidencia de los parámetros que afectan la calidad de la señal óptica en el desempeño de una red metropolitana WDM," (Trabajo de grado), Universidad del Cauca, Popayán, Colombia, 2008.

https://doi.org/10.13140/RG.2.2.21119.15529

[30] A. F. Escallón Portilla y V. H. Ruiz Guachetá, "Evaluación del desempeño a nivel físico de un sistema FTTH-GPON para servicios Quad Play al integrar un módulo RoF", (Tesis de Maestría), Universidad del Cauca, Popayán, Colombia, 2018. Disponible en: URL 